\title{
Removal of Azo dyes with Xanthan
}

\author{
Juan Antonio Lozano-Alvarez ${ }^{1 *}$, Juan Jáuregui-Rincón ${ }^{1}$, Iliana Medina-Ramírez ${ }^{2}$, Claudio Frausto- \\ Reyes $^{3}$, Rogelio Salinas-Gutiérrez ${ }^{4}$ \\ ${ }^{1}$ Departamento de Ingeniería Bioquímica, Universidad Autónoma de Aguascalientes, Av. Universidad \# 940 \\ Cd. universitaria, Aguascalientes, México, C.P. 20131. \\ ${ }^{2}$ Departamento de Química, Universidad Autónoma de Aguascalientes, Av. Universidad \# 940 Cd. \\ universitaria, Aguascalientes, México, C.P. 20131. \\ ${ }^{3}$ Centro de Investigaciones en Óptica, Unidad Aguascalientes, Prol. Constitución \# 607, Fracc. Reserva Loma \\ Bonita Aguascalientes, México, C. P. 20200. \\ ${ }^{4}$ Departamento de Estadística, Universidad Autónoma de Aguascalientes, Av. Universidad \# 940 Cd. \\ universitaria, Aguascalientes, México, C.P. 20131.
}

*Corresponding author: Juan Antonio Lozano-Alvarez, e-mail: : lozanoalvarez@yahoo.com Telephone: 52 (449) 9107400 Ext. 339. Fax: 52 (449) 9108410.

Received October 2 ${ }^{\text {th }}, 2018$; Accepted August 26, 2019.

DOI: http://dx.doi.org/10.29356/jmcs.v63i4.699

\begin{abstract}
The interaction among Xanthan (XANT) and three azo dyes: Direct blue 1 (DB1), Direct red 81 (DR81), and Direct black 22 (DB22) was studied. The Xanthan-dye-Al product was formed after the addition of $\mathrm{AlCl}_{3}$ to a Xanthan-Dye adduct containing solution. It was proposed that polyhydroxyoxoaluminum clusters named CAL-13 and CAL-30 react with this adduct producing a Xanthanate aluminum network, XANT-Al, and as a consequence a decrease in dye concentration in an aqueous medium was observed. The removal efficiencies obtained were the following: DB1 (99 \%), DB22 (99\%) and DR81 (94\%), demonstrating that this dye removal method is very efficient. The Zimm-Bragg model adequately described the experimental data and the order observed in the $\mathrm{Ku}$ (nucleation) and $\mathrm{U}$ (aggregation) parameters from this model was the following: DB1 $>$ DB22 $>$ DR81. Evidence suggests that physicochemical properties of dyes such as charge, molecular weight, aggregation ability and the capacity of XANT-Al to trap dye molecules are involved in the high removal values. Moreover, the dye binding mechanisms include electrostatic, hydrogen bonding and hydrophobic interactions that determine the magnitude of the parameters $\mathrm{Ku}$ and $\mathrm{U}$. These findings suggest that the XANT polymer is a good option to remove azo dyes from an aqueous medium.
\end{abstract}

Keywords: Xanthan; azo dyes; removal efficiency; polyhydroxyoxoaluminum cations; aggregation.

Resumen. Se estudió la interacción entre la xantana y tres colorantes azo: azul directo 1 (DB1), rojo directo 81 (DR81) y negro directo 22 (DB22). El producto Xantana-colorante-Al se formó tras la adición de cloruro de aluminio a una solución que contiene al aducto xantana-colorante. Se propuso que los cationes polihidroxioxoaluminio denominados CAL-13 y CAL-30 reaccionan con este aducto produciendo una red de xantanato de aluminio, XANT-Al, y como consecuencia se observó una disminución la concentración del colorante en medio acuoso. Las eficiencias de remoción obtenidas fueron las siguientes: DB1 (99 \%), DB22 (99 \%) y DR81 (94 \%). Demostrando que este método de remoción de colorantes es muy eficiente. El modelo de Zimm-Bragg describió adecuadamente los datos experimentales y el orden observado en los parámetros de este modelo, Ku (constante de nucleación) y U (parámetro de agregación) fue el siguiente: DB1>DB22> DR81. Las evidencias sugieren que propiedades fisicoquímicas de los colorantes como la carga, el peso molecular, 
capacidad de agregación y la habilidad del XANT-Al para atrapar moléculas de colorante están involucradas en los altos valores de remoción. Además, los mecanismos de enlace del colorante incluyen: interacciones electrostáticas, puentes de hidrógeno e interacciones hidrofóbicas que determinan la magnitud de los parámetros $\mathrm{Ku}$ y U. Estos hallazgos sugieren que el polímero XANT es una buena opción para remover a los colorantes azo del medio acuoso.

Palabras clave: Xantana; colorantes azo; eficiencia de remoción; cationes polihidroxioxoaluminio; agregación.

\section{Introduction}

Nowadays, considerable efforts are being made to assure the most efficient use of natural resources and a decrement on the impacts of pollution from industrial activities, however, some industrial processes are no sustainable, such as those applied in the textile industry, regarding the use of traditional methods of dyeing. In this sense, it has been reported that the transference of dyes from bulk solution to the textile garments is low (this phenomenon rarely reaches a total fixation of dye onto fiber surface), and as a consequence, considerable amounts of dyes go directly into the discharges from dyeing process [1]. In addition, the most abundant compounds used as textile dyes, belong to the azo dyes. The main characteristic of these compounds is the presence of the azo group (-N=N-) in their structure. Due to their diverse physicochemical properties, azo dyes are classified as: reactive, basic, acid, disperse, mordant and direct dyes [2]. Azo dyes are vivid colored substances that exhibit a high degree of chemical and photolytic stability, thus, disposal of these compounds into the environment, leads to a great impact in water bodies that act as receptors of the effluents containing azo dyes. The damages include teratogenic, mutagenic and carcinogenic effects on the organisms living in the aquatic ecosystems [3]. Therefore, adequate technologies must be used to remove these substances in the wastewaters produced by textile industry before being discharged to natural water bodies.

The use of different biopolymers has been explored as a sustainable strategy to reduce pollution. Xanthan (XANT) is an extracellular heteropolysaccharide produced by Xanthomonas campestris that has been widely used as thickening and stabilizing agent in food industry. This compound consists of a cellulose-like chain with trisaccharide side chains in an alternate pattern. These side chains contain one glucuronyl and two mannosyl residues attached at the C-3 position of the glucosyl residue. Each of the internal and terminal mannosyl residues of the side chain has an O-acetyl group at the C-6 position and a pyruvate ketal at the C-4 and C-6 positions, respectively [4].

Lately, different works have been reported on the use of XANT as hydrogel, grafted XANT and composites (including nanocomposites) to reduce the concentration of dyes and other contaminants in aqueous media [5-35]. For example, Makhado et al. [5] grafted XANT with acrylic acid through a free radical mechanism, and the resultant product removed a considerable amount of methylene blue (MB) $(149.5 \mathrm{mg} / \mathrm{g})$. On the other hand, magnetic nanoparticles have also been inserted into copolymers to improve their mechanic and separation properties in addition to removing dyes; Mittal et al. [6] obtained a hydrogel of XANTcopolymer mixture of poly(acrylic acid-co-acrylamide) filled with $\mathrm{Fe}_{3} \mathrm{O}_{4}$ magnetic nanoparticles that can be separated from aqueous solution by a magnetic field, and with a good efficiency to remove malachite green $(\mathrm{MG})(\mathrm{Qo}=497.15 \mathrm{mg} / \mathrm{g})$. Other nanocomposites containing silica based on XANT were produced by some research groups and removed congo red $(\mathrm{CR})(\mathrm{Qo}=209.2 \mathrm{mg} / \mathrm{g})[7], \mathrm{MB}(\mathrm{Qo}=497.5 \mathrm{mg} / \mathrm{g})$ and methyl violet $(\mathrm{MV})(\mathrm{Qo}=378.8 \mathrm{mg} / \mathrm{g})$ [8]. In the same way, XANT-derived materials have also been used to reduce other contaminants such as metal ions and organic compounds in aqueous medium. Pandey and Mishra synthesized the XANT-g-poly(ethylacrylate), which had an acceptable capacity to remove $\mathrm{Pb}^{+2}$ from aqueous solution (the value obtained for Qo at $\mathrm{pH}=5$ was $142.86 \mathrm{mg} / \mathrm{g}$ ) [9]. In the same order, poly(acrylic acid) grafted XANT had an good efficiency $(72.17 \%)$ in the removal of the inorganic mercury $\left(\mathrm{Hg}^{+2}\right)$ from an aqueous solution containing $300 \mathrm{mg} / \mathrm{L}$ from this metal ion [10]. Iftekhar et al. [11] used a XANT-layered double hydroxide nanocomposite to remove metal ions from rare earth elements, obtaining good maxima adsorption capacities $\left(\mathrm{Sc}^{+3}: \mathrm{Qo}=132.30 \mathrm{mg} / \mathrm{g}, \mathrm{Nd}^{+3}: \mathrm{Qo}=14.01 \mathrm{mg} / \mathrm{g}, \mathrm{Tm}^{+3}: \mathrm{Qo}=18.15 \mathrm{mg} / \mathrm{g}\right.$, and $\left.\mathrm{Yb}^{+3}: \mathrm{Qo}=25.73 \mathrm{mg} / \mathrm{g}\right)$ and finally it has been reported that organic compounds such as trichloroethylene was transformed $(65 \%$ from an aqueous solution containing $10 \mathrm{mg} / \mathrm{L}$ of this compound) by XANT-zero valent iron particles [12], and 
bisphenol A was adsorbed by the temperature-sensitive XANT-isopropylacrylamide hydrogel with a high efficiency (Qo $=458 \mathrm{mg} / \mathrm{g}$ ) [13]. Nonetheless, the XANT-derivatization or synthesis of nanocomposites demand a considerable cost in reagents and energy, and the biodegradability of these compounds is decreased [36-38].

In view of the above, we propose the use of natural XANT to avoid these disadvantages and simplify the use of this biopolymer to remove dyes from aqueous solution. This can be done in a simpler manner by mixing this polysaccharide with each of the dyes, then addition of $\mathrm{AlCl}_{3}$ results in instantaneous gel formation. The gel entraps dye molecules, reducing their concentration in aqueous medium (removal efficiencies greater than $94 \%$ were obtained). After the adduct (dye-biopolymer) is formed, the pollutant can be easily separated from solution. Moreover, this work is part of a major project that aims to eliminate (mineralize) dyes as environmental pollutants. In this way, the resultant product (XANT-Dye-Al) can be subjected to a physicochemical and/or biological treatment to reduce its environmental toxicity and thus achieve the final goal, that is, mineralization of the dye molecule.

\section{Experimental}

\section{Materials and Methods Chemicals}

Xanthan gum (sodium salt, $99 \%$ purity), $\mathrm{AlCl}_{3} * 6 \mathrm{H}_{2} \mathrm{O}(97 \%)$ and the dyes DB1 (80 \%) and DR81 (50 $\%)$ were purchased from Sigma-Aldrich and were used without further purification. The dye DB22 (50\% purity) was obtained from Mardupol and was used as received. Potassium bromide (spectrophotometric grade, containing $99.9 \%$ of this salt) was supplied by Merck.

\section{Optimization of dye removal conditions}

An aliquot $(40 \mathrm{~mL}$ ) of each dye (containing $250 \mathrm{ppm}$ ) was added to a $50 \mathrm{~mL}$ solution of the XANT (1 $\%)$ solution. Three different $\mathrm{pH}$ values were considered $(\mathrm{pH}$ values $=4,8$ and 12) with the addition of $\mathrm{NaOH}$ and $\mathrm{HCl}$ solutions. At the same time, the addition of $\mathrm{NaCl}$ crystals to these solutions produced three ionic strength values $(0.1 \mathrm{M}, 0.5 \mathrm{M}$ and $0.9 \mathrm{M})$ which were adjusted with a Corning Conductimeter checkmate II and the resulting final volumes and dye concentrations were $100 \mathrm{~mL}$ and $100 \mathrm{ppm}$ respectively. The experimental design included nine different solutions resulting from two factors ( $\mathrm{pH}$ and ionic strength) at three different levels (pH: 4, 8 and 12) and ionic strength $(0.1 \mathrm{M}, 0.5 \mathrm{M}$ and $0.9 \mathrm{M})$ and four points at the center consisting in samples with $\mathrm{pH}=8$ and ionic strength $=0.5 \mathrm{M}$ values. All experiments were carried out by triplicate. Samples were cap sealed and shaken $(200 \mathrm{rpm})$ for 1 day at $27^{\circ} \mathrm{C}$ in dark conditions. After that, an aliquot consisting of $30 \mathrm{~mL}$ of $\mathrm{AlCl}_{3} 5 \% \mathrm{w} / \mathrm{v}$ solution was added to each sample to promote gel formation. Later, a final volume of $200 \mathrm{~mL}$ was adjusted by addition of distilled water. All samples remained at room temperature $\left(27^{\circ} \mathrm{C}\right)$ during $24 \mathrm{~h}$ and the equilibrium dye concentration was measured by UV-Vis spectrophotometry.

\section{Removal Isotherms}

A $2000 \mathrm{ppm}$ dye solution was prepared with an optimal $\mathrm{pH}$ and ionic strength values obtained from optimization studies in order to achieve a complete saturation of the XANT. Solutions from different concentration were prepared ranging from 5-2000 ppm.

After the addition of $0.5 \mathrm{~g}$ of the XANT powder to each solution all vials were capped, sealed, and maintained for $20 \mathrm{~h}$ at room temperature $\left(27^{\circ} \mathrm{C}\right)$ to allow hydration. Afterwards, the samples were shaken $(200$ $\mathrm{rpm}$ ) for $20 \mathrm{~h}$ at the same temperature in dark conditions. Finally, each system was treated as described above to form the gel consisting of the XANT-Dye-Al product. UV-Vis spectroscopy was used to determine the amount of the dye captured by the XANT and the unbound dye concentration at equilibrium state (Ceq).

\section{Application of Zimm-Bragg model to experimental Isotherms.}

The nucleation $(\mathrm{Ku})$ and aggregation $(\mathrm{U})$ parameters of the Zimm-Bragg model [39] were determined for each system through the corresponding experimental data and a computational routine implemented in the $\mathrm{R}$ 
statistical software, which has been created and developed by the R Project for Statistical Computing [40]. The reported parameters in this investigation are optimal in the sense that they minimize the sum of relative errors given by the equation 1 :

$$
L\left(K_{u}, u\right)=\sum_{i=1}^{n}\left(\frac{\beta_{i}-\hat{\beta}_{i}}{\beta_{i}}\right)^{2}
$$

where $\beta_{\mathrm{i}}$ is the $\mathrm{i}$-th experimental value and $\beta \hat{\mathrm{i}}$ represents the $\mathrm{i}$-th theoretical value described by the ZimmBragg model.

\section{UV-Visible studies}

All the electronic absorption spectra of the dyes in an aqueous medium (400 to $800 \mathrm{~nm}$ ) were performed in a Thermospectronic spectrophotometer (model Genesys 2) at three different conditions as follows:

a) Effect of $\mathrm{pH}$ : Different aqueous solutions containing each dye $\left(1 * 10^{-5} \mathrm{M}\right)$ were adjusted from low $\mathrm{pH}$ value to high $\mathrm{pH}$ and their UV-Visible spectra were obtained.

b) Effect of dye concentration in the absence and presence of the XANT: Different dye concentration solutions were prepared (5-100 mg L-1) at different values of $\mathrm{pH}$ and ionic strength corresponding to each dye in an aqueous solution. The electronic absorption spectra of each dye were acquired in the presence of XANT $(1 \% \mathrm{w} / \mathrm{v})$ and in the absence of this biopolymer with the goal of study the effect of this polysaccharide on the dye aggregation phenomenon.

c) Effect of gelling agent: This procedure includes that described in the previous paragraph (b), but an additional step corresponding to the addition of $\mathrm{AlCl}_{3}(5 \% \mathrm{w} / \mathrm{v})$ and a resting period of $24 \mathrm{~h}\left(27^{\circ} \mathrm{C}\right)$, in order to produce a gel corresponding to the compound XANT-Dye-Al.

In all cases the width of the cell was modified to obtain absorbance values below two, therefore the relationship between absorbance and concentration does not remain linear.

\section{IR and Raman studies}

The Raman spectra of pure dyes were obtained from their original powder commercial presentation. The XANT-Dye-Al products were isolated and purified as follows: The gelled product was separated by filtration, washed at least five times with distilled water, dried at $50^{\circ} \mathrm{C}(48 \mathrm{~h})$ and grounded in a mortar. It is important to mention that the powder sample corresponds to the product that resulted from the last point of the removal isotherm, which contains the highest concentration of dye in the gel. The samples were analyzed by a MicroRaman system (Renishaw 1000) to obtain the Raman spectra from $2000-400 \mathrm{~cm}^{-1}$.

In the case of FT-IR studies, the samples including DR81 and DB22 dyes were analyzed in a Perkin Elmer 1600 series with potassium bromide pellets using transmission mode and ATR mode was used for DB1 (Thermo scientific Nicolet iS10, using a Germanium window). All the spectra were performed in the 4000-650 $\mathrm{cm}^{-1}$.

\section{Results and discussion}

\section{Sorption studies}

The effect of $\mathrm{pH}$ and ionic strength on the removal efficiency for the systems XANT-DB1-Al (Fig. 2(a)), XANT-DR81-Al (Fig. 2(b)), and XANT-DB22-Al (Fig. 2(c)) is schematically presented in Fig. 2. From Fig. 2(a) it can be observed that $\mathrm{pH}$ has a greater influence on the removal of DB1 dye. In this sense, when the $\mathrm{pH}$ is increased the dye removal efficiency is enhanced in such a manner that high removal values were obtained (removal percentages higher than $99 \%$ were obtained at $\mathrm{pH}=12$ and ionic strength from $0.1 \mathrm{M}$ to $0.9 \mathrm{M}$ ), while at $\mathrm{pH}=4$ the dye removal efficiency resulted in $97 \%$. 
As can be seen in Fig. 1(a), the DB1 molecules have a lower negative charge at acidic $\mathrm{pH}$ values than when they are dissolved in an aqueous medium with basic $\mathrm{pH}$ values. Nonetheless, the Fig. 2(a) shows an inverse tendency, which suggest that when the DB1 solution interacts with XANT in an aqueous solution, is due to the existence of different functional groups in this dye such as amino, sulfonate, hydroxyl, azo and methoxy, which can form hydrogen bonding with the hydroxyl group, oxygen atom from hemiacetal and glycosidic bonds from residues included in the "trimmer" (internal mannose, glucuronic acid and external mannose) attached to the main chain of XANT skeleton. Moreover, it is known that DB1 dye has a great ability to form aggregates, resulting in its adsorption to XANT molecular surface and increased removal efficiency [41].

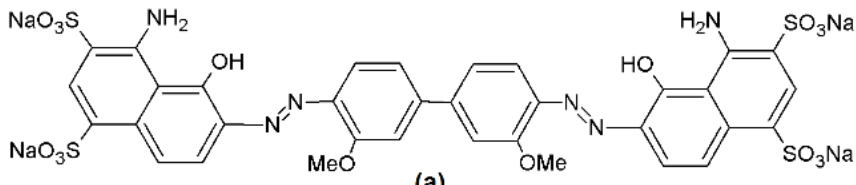

(a)

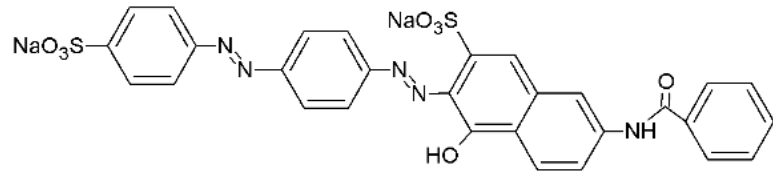

(b)

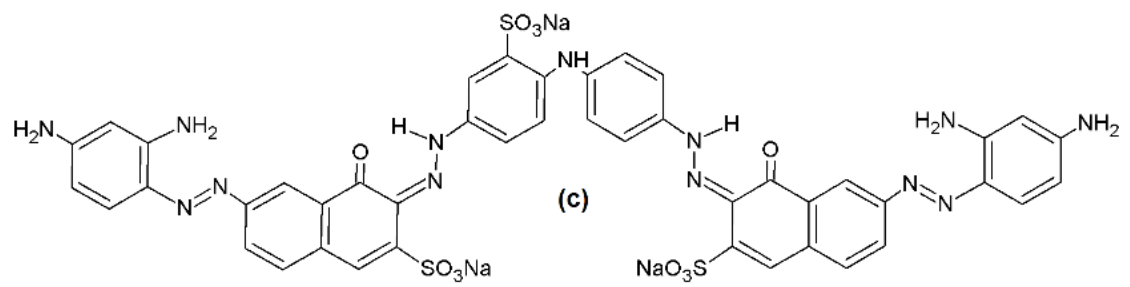

Fig. 1. The structure of Azo dyes: (a) Direct blue 1 (DB1), (b) Direct red 81(DR81), and (c) Direct black 22 (DB22).

On the other hand, at high ionic strength values $\left(>0.1 \mathrm{M}\right.$ at $\left.25^{\circ} \mathrm{C}\right)$, the xanthan exhibits a double helix conformation and forms aggregates in acidic or basic conditions [42-45], which allow stronger interactions amongst the trisaccharide side group and the dye. In the same way, when the $\mathrm{pH}$ is increased although the DB1 charge is negative (-4 at $\mathrm{pH}=12$, see Fig. 1(a)), it is attracted by chemical species of aluminum (III) bounded to XANT. In the same sense, the affinity from XANT to $\mathrm{Al}^{3+}$ ion rises in such way that highest removal efficiencies are obtained at $\mathrm{pH}=12$. It was proposed [46, 47], that glucuronate group attached to XANT molecules binds to $\mathrm{Al}^{3+}$ in such way that this ion act as a linker between XANT molecules, resulting in a polymeric network that can be seen in a macroscopic way as a "strong gel". However, recently it has been encountered that $\mathrm{Al}^{+3}$ in aqueous solution, has a high tendency to form the following polyhydroxyoxoaluminum clusters: $\left[\mathrm{Al}_{13} \mathrm{O}_{4}(\mathrm{OH})_{24}\left(\mathrm{H}_{2} \mathrm{O}\right)_{12}\right]\left[\mathrm{SO}_{4}\right]_{4} \cdot 19 \mathrm{H}_{2} \mathrm{O}$ (which will be denominated as CAL-13) and $\left[\mathrm{Al}_{30} \mathrm{O}_{8}(\mathrm{OH})_{56}\right.$ $\left.\left(\mathrm{H}_{2} \mathrm{O}\right)_{26}\right]\left[\mathrm{SO}_{4}\right]_{9} \cdot \times \mathrm{H}_{2} \mathrm{O}$ (this cluster will be named CAL-30), which is approximately $2 \mathrm{~nm}$ in length)[48, 49]. These findings suggest that when $\mathrm{pH}$ is increased, the affinity of XANT to CAL-13 and CAL-30 clusters is strongly elevated as a consequence of the electrostatic interaction between clusters and the XANT molecules. This force is so strong that the presence of salts (ionic strength from $0.1 \mathrm{M}-0.9 \mathrm{M}$ ) does not affect the removal efficiency independent of the $\mathrm{pH}$ value, as can be observed in Fig. 2, only acidic $\mathrm{pH}$ values reduced the DB1 removal values due to the protonation of carboxyl groups from glucuronic and pyruvic acid moieties and 
consequently the reduction of negative charge from XANT (which pKa value ranges from 2.5-3.5) at the experimental conditions performed in this study [50].

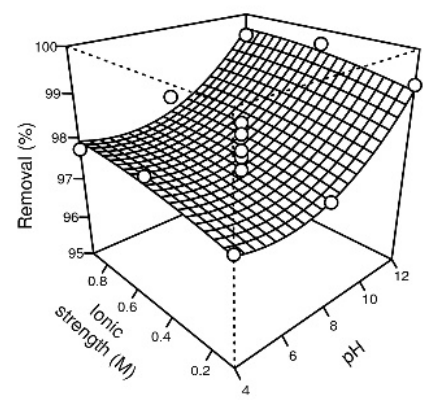

(a)

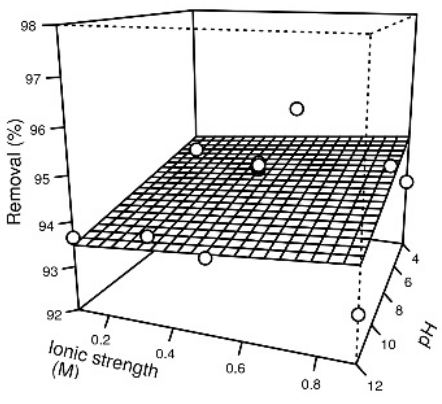

(b)

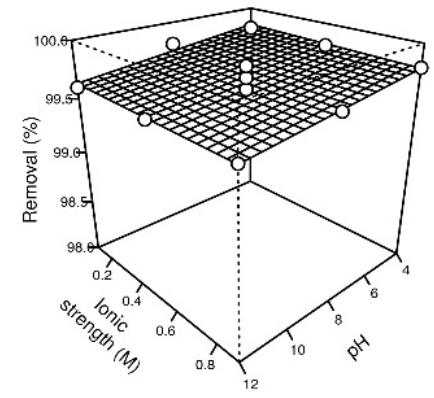

(c)

Fig. 2. Graphical representation of the Removal efficiency as a function of $\mathrm{pH}$ and ionic strength for the following systems: (a) XANT-DB1-Al, (b) XANT-DR81-Al, and (c) XANT-DB22-Al. The white circles represent the experimental data and the surfaces show the theoretical behavior obtained from the statistical treatment of experimental data.

In addition, we propose that the trisaccharide side chains from XANT react with $\mathrm{AlCl}_{3}$, then the gel formation give rise to cavities into the aluminum xanthanate (XANT-Al) network that "trap" DB1 molecules adsorbed to XANT molecular surface, increasing the removal of this dye. From these observations involved in the removal of DB1, we propose to describe the global removal phenomenon as a "dye entrapment" that resulted in a $99 \%$ of removal efficiency $(\mathrm{pH}=12$ and ionic strength of $0.9 \mathrm{M})$.

The influence of $\mathrm{pH}$ and ionic strength on the XANT removal efficiency of DR81 is depicted in Fig. 2(b). Interestingly, the influence of $\mathrm{pH}$ on removal efficiency has an opposite tendency with respect to that observed with the product XANT-DB1-Al. As can be seen in the Fig. 1(b), the DR81 dye has a smaller negative charge in comparison to DB1 at all the $\mathrm{pH}$ values considered in this work $(\mathrm{pH}=4-12)$, and as consequence the repulsion force experimented between DR81 and XANT molecules is lower than that observed in the system XANT-DB1-Al. Moreover, at acidic pH there is a smaller repulsion, because the carboxyl group from glucuronic and pyruvic acids are partially protonated, allowing a major role of the hydrogen bonds and the hydrophobic interactions formed among the DR81 and XANT molecules and promoting a high removal efficiency $(95 \%)$ at $\mathrm{pH}=4$ than at basic $\mathrm{pH}(93 \%$ at $\mathrm{pH}=12)$. Oakes and Dixon [51], have proposed that the dyes with high aggregation capacity possess an elevated number of aromatic moieties such as phenyl, naphthyl, etc. From the fig. 1b, it can be deduced that the aggregation ability of DR81 is lower than that showed by DB1, because its molecular structure has only one naphthyl and three phenyl rings, which resulted in a lower removal efficiency. 
On the other hand, and from Fig. 2(b) it appears to be that the addition of $\mathrm{AlCl}_{3}$ does not have the same influence than that observed in DB1, and in consequence the influence of the ionic strength is beneficial to the dye's removal efficiency. This means that an increase in ionic strength diminish the repulsion between DR81 and XANT molecules and improve the removal ability of the XANT-Al network. From these results it can be proposed that DR81 has a higher tendency to bind with the XANT molecules than that observed for DB1, but due to its low aggregation capacity and smaller negative charge, after the addition of $\mathrm{AlCl}_{3}$ only a few molecules of this dye are attracted by CAL-13 and CAL-30 clusters.

Fig. 2(c) shows the removal efficiency of DB22 as a function of the $\mathrm{pH}$ and ionic strength in the system XANT-DB22-Al. Interestingly, from this figure it can be observed that the removal percentage values are the highest of the three systems (from $99.5 \%$ to $99.8 \%$ ). In the same manner, it can be seen that at $\mathrm{pH}=4$ the biggest removal efficiencies are obtained because the net charge of DB22 (+2) at this pH value, resulting of the presence of five amino and three sulfonate groups, favors the existence of electrostatic interactions with the partially ionized XANT molecule. On the other side, at basic $\mathrm{pH}$ values the negative charge of DB22 results to be -5 as result of the ionization of its sulfonate, amino and hydroxyl groups, and each basic pentameric unit which belongs to XANT polysaccharide possess a negative charge corresponding to -2 due to total ionization of carboxyl groups attached to glucuronic and pyruvic acid residues. As a consequence, there are repulsion forces between XANT and DB22 molecules, which affect negatively the removal percentage of this dye. Nevertheless, it is important to mention that the existence of hydrogen bonding and hydrophobic interactions in the XANT-DB22 still contribute to the high removal of DB22 by XANT. In the same way, after the addition of $\mathrm{AlCl}_{3}$ solution, the network of XANT-Al promotes a decrease in the negative charge from XANT favoring the adsorption of DB22 molecules onto the XANT molecular surface. Additionally, an attraction force is originated between the polyhydroxyoxoaluminum clusters (CAL-13 and CAL-30) and DB22 molecules, and the cavities originated in the XANT-Al network "traps" the molecules and aggregates from DB22 dye. As was mentioned before, and in accordance with Oakes and Dixon [51], high aggregation ability showed by DB22 is due to the presence of two naphthyl and four phenyl rings, contributed to obtain a great removal percentage of this dye by XANT. In the same way that DR81, figures 1(c) and 2(c) show that electrostatic interaction between XANT and DB22 (at low pH values) and that involving the clusters CAL-13 and CAL-30 and DB22 (at basic $\mathrm{pH}$ values) are almost unaffected by the ionic strength, demonstrating their great contribution in the removal of this dye by using XANT biopolymer, resulting a removal percentage of $99.8 \%$ at $\mathrm{pH}=4$ and $0.1 \mathrm{M}$.

\section{Removal Isotherms}

Although the models proposed by Langmuir [52] and Freundlich [53] have been widely used in the removal of dyes using different materials [54], it was reported that in case of the alginic acid-dye and the XANTdye systems, these models do not describe adequately the experimental data because it was proposed that these polysaccharides bind the dye molecules and their aggregates, but at the same time flocculate and "trap" them through the formation of a network that macroscopically can be seen as a gel [55]. In this sense, is considered that the fundamental basis from Langmuir and Freundlich models do not apply for the systems including both the XANT-Al and alginic acid as calcium salt.

The Zimm-Bragg model fits adequately to the experimental data from systems including the binding of cationic surfactants to materials such as, alginate, pectate, polyacrylate, carboxymethylcellulose [56], polyacrylamide sulfonate [57], and XANT [58]. These findings suggest that the mathematical form of this model can describe the binding of monomeric or aggregated surfactant molecules (micelles) to the molecular surface of different polymers and from mathematical point of view, the binding of single dye molecules and dye's aggregates to the XANT molecular surface are similar phenomena to that occurred in surfactant-polymer systems, only that when we are working with dyes, we say "aggregates" instead of micelles.

This model is based in two principal processes:

1) Nucleation: It is represented by $\mathrm{Ku}$, whose magnitude is related with the ability from one dye molecule in the bulk solution to bind at adjacent site to other occupied by another bounded dye onto the XANT molecular surface. The magnitude of $\mathrm{Ku}$ is determined as follows:

$$
K u=\frac{(D D)}{(E D)(D)}
$$


where, D represents to one dye molecule bound onto the XANT molecular surface, DD denotes the occupation of two adjacent sites where two molecule dyes are adsorbed to XANT and E indicates an empty or unoccupied binding site located at the molecular surface of this polysaccharide.

2) Cooperativity: It is related with the aggregation ability of dye molecules once they have been bound onto XANT molecular surface, it is represented by $\mathrm{U}$, which is defined by the following equation:

$$
U=\frac{(D D)(E E)}{(D E)^{2}}
$$

Additionaly, the Zimm-Bragg model includes an independent variable named binding coefficient ( $\beta$ ), defined as the ratio between the sites occupied by bounded dye molecules onto XANT and the total sites that can bind dye molecules in all sites located at the molecular surface of this biopolymer. The equation that relates $\beta$ with $\mathrm{Ku}$ and $\mathrm{U}$ parameters is the following:

$$
\beta=\frac{1}{2}\left\{1+\frac{s-1}{\left[(1-s)^{2}+\left(\frac{4 s}{u}\right)\right]^{\frac{1}{2}}}\right\}
$$

With $\mathrm{s}=\mathrm{Ku} \cdot \mathrm{Ceq}$ and where Ceq represents the dye concentration that remains in the bulk solution at the equilibrium state. In the same order, to obtain the initial values of $\mathrm{Ku}$ and $\mathrm{U}$, the equations 5 and 6 can be applied to the experimental data.

$$
\begin{aligned}
& \operatorname{Ceq}(\operatorname{in} \beta=0.5)=1 / K u \\
& {\left[\frac{d \beta}{\log C e q}\right] \operatorname{in} \beta=0.5=U^{1 / 2} / 4}
\end{aligned}
$$

Once that $\mathrm{Ku}$ and $\mathrm{U}$ values were determined in an approximate way, they can be used to perform the optimization process to give rise to the theoretical values of nucleation and aggregation constants, which can describe the experimental isotherm.

The experimental data and theoretical curves obtained from the Zimm-Bragg model applied to all systems are depicted in Fig. 3 and the values of the Ku and $\mathrm{U}$ parameters are compiled in Table 1. Interestingly, from sorption studies where only one dye concentration value $(100 \mathrm{ppm})$ was used, the order found in the removal efficiency was the following: DB22 DB1 $>$ DR81. In the case of experimental isotherms, different concentration values (5-2000 ppm) were contacted with the dyes and the new order obtained was as follows: DB1 $>$ DB22>DR81. In this sense, the Ku and $\mathrm{U}$ values written in table 2 involve different phenomena such as:

1) The electrostatic interactions between the dyes and the clusters CAL-13 and CAL-30, when the gel of XANT-Al is formed, which is related directly with the net charge of dye molecules and those of polyhydroxyoxoaluminum clusters.

2) The existence of hydrogen bonding and hydrophobic interactions between XANT and dye molecules, which are dependent of functional groups of these molecules. 
3) The aggregation ability of each dye, which is related with the presence of aromatic rings in its structure and its molecular weight (and as a consequence, their size).

4) The entrapment ability performed by the XANT-Al, resulting from the formation of cavities when the XANT polymer and $\mathrm{AlCl}_{3}$ react to form a gel.

The high values of $\mathrm{Ku}$ and $\mathrm{U}$ showed by the XANT-DB1-Al product $\left(\mathrm{Ku}=1,090,645.4 \mathrm{~mol} \mathrm{Kg}^{-1}\right.$ and $\mathrm{U}=41.483$ respectively), are the result of a great electrostatic attraction between the clusters CAL-13 and CAL-30, which have a high positive charge and the DB1 molecules which possess a great negative charge at $\mathrm{pH}=12$. In the same way, at this $\mathrm{pH}$ value the attraction between the XANT double helixes and these polyhydroxyoxoaluminum clusters (CAL-13 and CAL-30) reaches a maximum, and the amount of these clusters "linking" the XANT molecules, is bigger than that observed at acidic $\mathrm{pH}$. As a consequence, the amount of DB1 adsorbed to theses clusters is the highest for all the systems under study. As was mentioned before, the functional groups attached to DB1 molecules can form hydrogen bonds with the XANT functional groups and the hydrophobic interactions are present in the adduct XANT-DB1 as can be deduced from spectroscopic studies (see next section). If it is considered that there are a defined number of dye binding sites on the XANT molecular surface, then it is possible that the bigger the dye the higher the removal efficiency. In the case of DB1 dye (whose molecular weight, $\mathrm{MW}=992.80 \mathrm{~g} \mathrm{~mol}^{-1}$ ), this factor favors in a considerable way the removal of this compound by XANT polysaccharide. In addition, the presence of aromatic rings ( 2 naphthyl and 2 phenyl rings) promotes a high planarity that causes a high aggregation capacity [41, 51]. Finally, in the process of XANT-Al network formation, cavities and spaces would be created, where DB1 molecules and aggregates could be "trapped" resulting in the $\mathrm{Ku}$ and $\mathrm{U}$ values obtained for this system.

The corresponding values of $\mathrm{Ku}=151,370.4 \mathrm{~mol} \mathrm{Kg}^{-1}$ and $\mathrm{U}=18.375$ obtained from the XANT-DB22-Al system are smaller than that observed in the XANT-DB1-Al system but greater than that corresponding to the XANT-DR81-Al system, as illustrated in the Table 1 and in the Fig. 3. From this figure, a high concordance between the theoretical curve and the experimental isotherm can be observed. As was mentioned above, there is an electrostatic repulsion between CAL-13 and CAL-30 cations, and DB22 molecules, because these chemical species have positive charge at $\mathrm{pH}=4$, and as a consequence a drastic decrease in the values of the $\mathrm{Ku}$ and $\mathrm{U}$ parameters was found. On the other hand, XANT molecules attracted the DB22 molecules with opposite charge and additionally considerable hydrogen bonds were formed by the functional groups from both compounds. Moreover, the big size of DB22 molecules and their high aggregation ability promoted hydrophobic interactions with enough magnitude to favor significant values of $\mathrm{Ku}$ and $\mathrm{U}$ parameters. However, an important competence between DB22 and the polyhydroxyoxoaluminum clusters for XANT binding sites, diminished the values of nucleation and cooperativity parameters for this system.

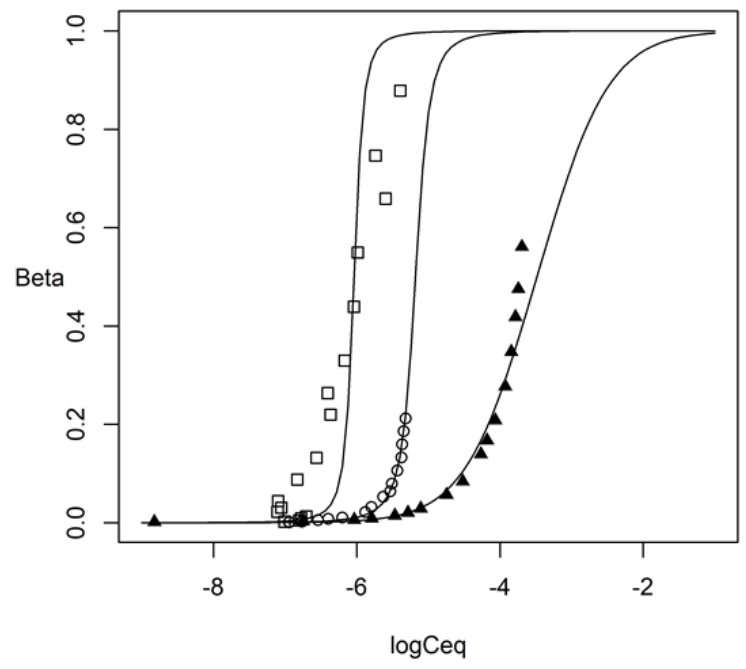

Fig. 3. Experimental data and theoretical Isotherms obtained from equation 3 for the following systems: XANT-DB1-Al (Open squares), XANT-DB22-Al (open circles), and XANT-DR81-Al (closed triangles). The continuous lines represent the theoretical isotherms for each of these systems. 
Table 1. Parameters obtained when the Zimm-Bragg model is applied to the experimental data of the XANTDye-Al systems.

\begin{tabular}{|c|c|c|c|}
\hline System & XANT-DB1-Al & XANT-DB22-Al & XANT-DR81-Al \\
\hline $\mathrm{Ku}\left(\mathrm{mol} \mathrm{Kg}^{-1}\right)$ & $1,090,645.4$ & $151,370.4$ & $3,044.2$ \\
\hline $\mathrm{U}$ & 41.483 & 18.375 & 0.74964 \\
\hline $\mathrm{R}^{2}$ & 0.7619 & 0.9899 & 0.91781 \\
\hline $\mathrm{ARE}^{\mathrm{a}}$ & 56.41 & 25.19 & 24.48 \\
\hline
\end{tabular}

${ }^{a}$ Average relative error

The nucleation and cooperativity parameters corresponding to the XANT-DR81 system were $\mathrm{Ku}=$ $3,044.2 \mathrm{~mol} \mathrm{Kg}^{-1}$ and $\mathrm{U}=0.7496$ respectively, and the experimental isotherm and the theoretical curve obtained from the substitution of these values in the equation (4) is showed in the Fig. 3. These results and those obtained in the sorption studies section, show that XANT has the lowest removal efficiency and smallest values of Ku and $\mathrm{U}$ parameters for DR81 dye. Taking into account that this dye has negative charge, it can be possible that some mechanisms involved in their removal are similar to the observed in the XANT-DB1-Al system but with some important differences. For example, exists an attraction force between DR81 molecules and the polyhydroxyoxoaluminum clusters, but this is weaker than that encountered in the XANT-DB1-Al system. Moreover, the low value of cooperativity parameter, suggest a poor aggregation tendency of this dye after XANT-DR81-Al product is formed, because the DR81 molecule has the smallest molecular weight (MW = $675.61 \mathrm{~g} \mathrm{~mol}^{-1}$ ) and the number of aromatic rings attached to it is small compared with the other dyes. Nevertheless, the hydrogen bonding, the hydrophobic interactions and the entrapment of DR81 molecules seems to be enough to allow considerable $\mathrm{Ku}$ and $\mathrm{U}$ values when XANT is used as removal agent in an aqueous environment.

\section{Spectroscopic studies UV-Visible studies}

The interactions of XANT and dye molecules were closely analyzed by UV-Vis spectroscopy. Recently, it was reported that the absorption electronic spectrum of DB1 in the $\mathrm{pH}$ range 4-9 does not show changes, but when the $\mathrm{pH}$ value is increased to $\mathrm{pH}=12$, an important shift in the absorption maximum wavelength of this dye $\left(\lambda_{\max }\right)$ was experimented from $\lambda_{\max }=618 \mathrm{~nm}$ at $\mathrm{pH}=9$ to $\lambda_{\max }=584 \mathrm{~nm}$ at $\mathrm{pH}=12$ [59]. It was proposed that these changes indicate that DB1 remains as hydrazone tautomer at $\mathrm{pH}$ slightly basic (below to $\mathrm{pH}=9$ ), but at $\mathrm{pH}=12$ the common anion is formed as a result of the ionization process of hydrazone tautomer as was reported by different authors (see Fig. 4) [60, 61].

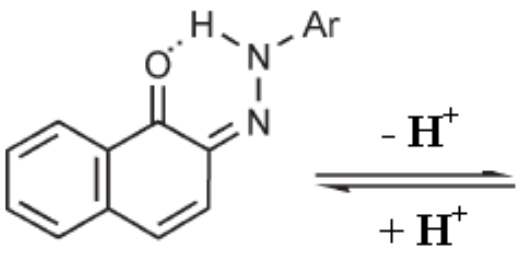

\section{Hydrazone form}<smiles>[O-]c1c(/N=N/[Al])ccc2ccccc12</smiles>

Common anion

Fig. 4. Graphical representation of the ionization process of one azo dye in its hydrazone form that gives rise to the "common anion" at basic $\mathrm{pH}$ values.

It was reported that dyes with a high number of aromatic rings that favor a planar structure, have a great tendency to form $\mathrm{H}$ aggregates due to the $\pi-\pi$ stacking interactions between these rings, additionally the functional groups attached to dye molecule are oriented in such a way that the repulsion forces experienced 
among them are minimum [51]. Furthermore, dyes with high molecular weight will have greater ability to aggregate than small dye molecules [62]. It was encountered that DB1 forms dimers and trimmers at similar conditions to those used in this work [41], and interestingly, the anionic form (common anion) of this dye has a significant ability to remain aggregated as was reported by Lozano-Alvarez et al. [59].

When DB1 dissolved at $\mathrm{pH}=12$ in an aqueous medium is mixed with XANT, it is observed that the DB1 aggregates exist at this $\mathrm{pH}$ value with high dye concentrations (Fig. 5), but when the amount of dye is decreased, the $\lambda_{\max }$ is displaced from $\lambda_{\max }=584 \mathrm{~nm}\left(100 \mathrm{mg} \mathrm{L}^{-1}\right)$ to $\lambda_{\max }=618 \mathrm{~nm}\left(5 \mathrm{mg} \mathrm{L}^{-1}\right)$. It means that when the DB1 concentration is low, the DB1 molecules are adsorbed to the XANT in such a way that the number of DB1 aggregates in the presence of this biopolymer was diminished. If the concentration of the dye is increased, then the DB1 molecules tend to form bigger aggregates on the molecular surface of this polysaccharide. It is important to mention that XANT is a hydrocolloid that when is hydrated, the aqueous solution that contains it, appears to have a low opacity that affects the UV-Visible spectra of the different XANT-Dye solutions and in some occasions certain level of noise can be observed as a consequence of this XANT property, but this does not avoid the location of $\lambda_{\max }$ in the distinct spectra. The XANT polymer possesses cellulose-like backbone covered by a trisaccharide side group by each pentameric unit, this moiety protects, and provides a high stability to this polymer and its structure has hydrophobic regions [63]. Moreover, the XANT possess a small negative charge that permits the adsorption of the DB1 molecules onto its surface trough hydrogen bonding and hydrophobic interactions and it is possible the creation of nucleation centers that bind more DB1 molecules and favor an aggregation process.

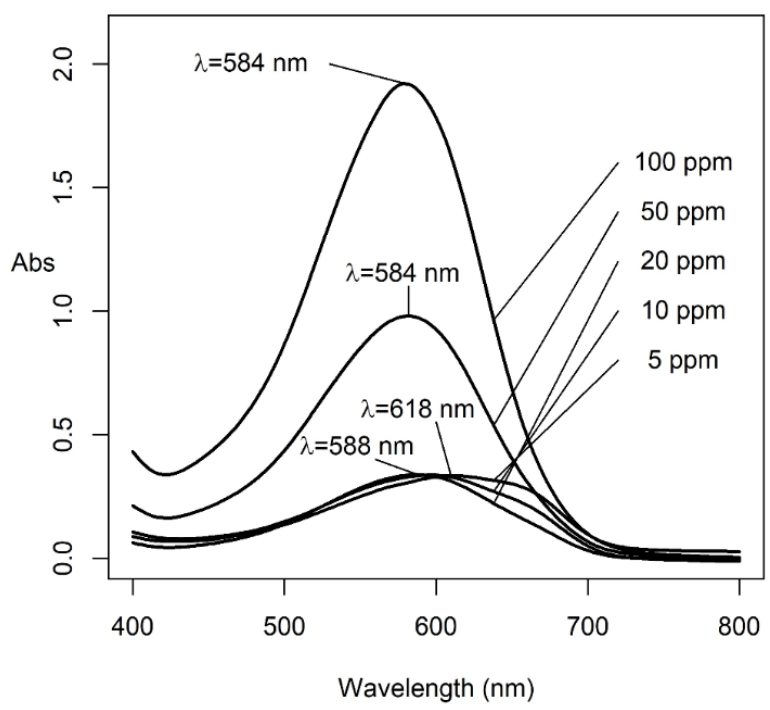

Fig. 5. UV-Visible absorption spectra of the DB1 at different concentration values in the presence of XANT $(1 \% \mathrm{w} / \mathrm{v}, \mathrm{pH}=12)$.

Fig. 6 depicts the spectra of XANT-DB1 (a) and XANT-DB1-Al (b). From this figure, it is observed that the spectrum of XANT-DB1, after the the addition of $\mathrm{AlCl}_{3}$ results in a red shift from $\lambda_{\max }=584 \mathrm{~nm}$ to $\lambda_{\max }$ $=610 \mathrm{~nm}$ and a shoulder located at $645 \mathrm{~nm}$. As discussed in the sorption studies section, the polyhydroxyoxoaluminum cations attract the DB1 molecules through electrostatic interactions and fragments the aggregates formed in the XANT-DB1 adduct. From the magnitude of this displacement it can be assumed that some fraction of total molecules are in monomeric form of DB1 in the XANT-DB1-Al compound. It was found that when this dye is encountered in its monomeric form, the spectrum shows a band centered at $620 \mathrm{~nm}$ (this signal is close to the band found in $610 \mathrm{~nm}$ in the XANT-DB1-Al spectrum), and this same research group 
observed a band located at $656 \mathrm{~nm}$ resulting from the interaction between DB1 and celophane, and it was suggested a low aggregation degree of this dye [64].

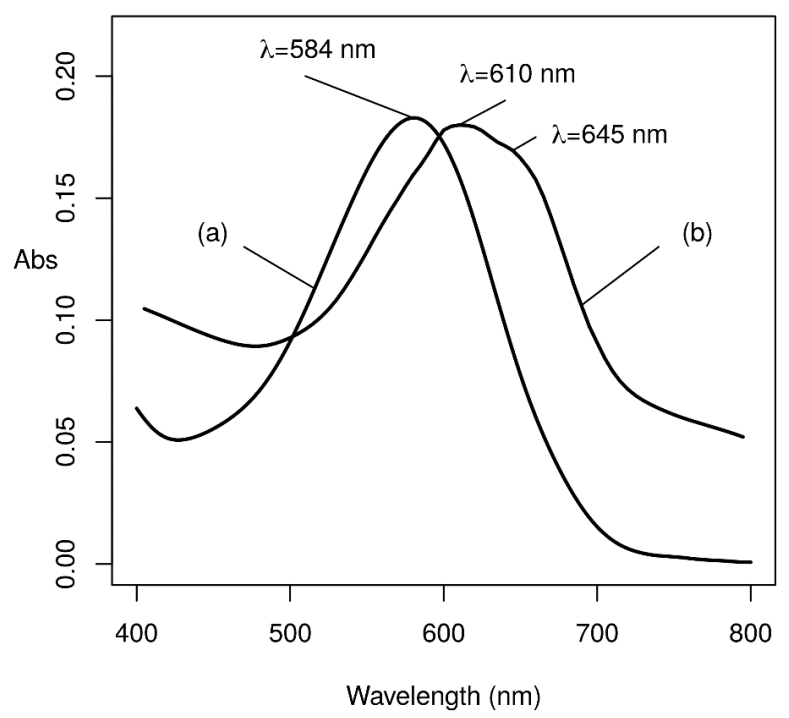

Fig. 6. UV-Visible absorption spectra of the (a) XANT-DB1, and (b) XANT-DB1-Al gel.

The shoulder showed in fig. $6(\mathbf{b})\left(\lambda_{\max }=645 \mathrm{~nm}\right)$ suggests that the chemical environment surrounding the DB1 molecules in the XANT-DB1-Al aproximates to that found in celophane $\left(\lambda_{\max }=656 \mathrm{~nm}\right)$, which corroborates the existence of the interaction previously proposed among the XANT and DB1 molecules. Both signals $\left(\lambda_{\max }=610 \mathrm{~nm}\right.$ and $\lambda_{\max }=645 \mathrm{~nm}$ ) indicate the existence of at least two different chemical species of the DB1 dye, one of them attracted to the polycations CAL-13 and CAL-30, and the other bound to the XANT molecule through hydrogen bonding and hydrophobic interactions.

As was reported previously, the $\mathrm{pH}$ effect on the electronic absorption of DR81 is similar to that observed in the DB1 dye [59]. For example, in solutions containing DR81 dye at $\mathrm{pH}$ values lower than 10, a $\lambda_{\max }$ at $512 \mathrm{~nm}$ is observed, whereas at higher $\mathrm{pH}(11.5)$, this maximum is displaced to $\lambda_{\max }=560 \mathrm{~nm}$, suggesting the presence of hydrazone tautomeric form of this dye in aqueous medium. This same group found, that a light hypsochromic shift is originated from $\lambda_{\max }=512 \mathrm{~nm}$ to $\lambda_{\max }=509 \mathrm{~nm}$, when the concentration value of DR81 es increased from $5 \mathrm{ppm}$ to $100 \mathrm{ppm}$ at $\mathrm{pH}=4$, supporting a dye aggregation phenomenon, but with lower magnitude than that observed with DB1. This experimental finding is consequence of a smaller DR81 molecular weight, and lower number of aromatic rings than those attached to DB1 molecules.

Fig. 7 shows the UV-Visible absorption spectra of DR81 at different concentration values in the presence of XANT $(1 \% \mathrm{w} / \mathrm{v}, \mathrm{pH}=4.0)$. As was mentioned before, the presence of XANT molecules cause an analogous effect on DR81 dye as that observed with DB1. As can be seen in the fig. 7, at low dye concentration $(5 \mathrm{ppm})$, the UV-Visible absorption spectrum shows a $\lambda_{\max }=535 \mathrm{~nm}$ and at $100 \mathrm{ppm}$ ocured a hypsochromic shift to $\lambda_{\max }=509 \mathrm{~nm}$, i.e. a $\Delta \lambda_{\max }=26 \mathrm{~nm}$ between both the aggregated and the dissagregated forms confirms a smaller aggregation ability of DR81 than that showed by DB1 in the presence of XANT. Moreover, it is proposed from these results that the adsorption force experimented between XANT and DR81 dye is stronger than that observed in the adduct XANT-DB1 before the addition of $\mathrm{AlCl}_{3}$. 


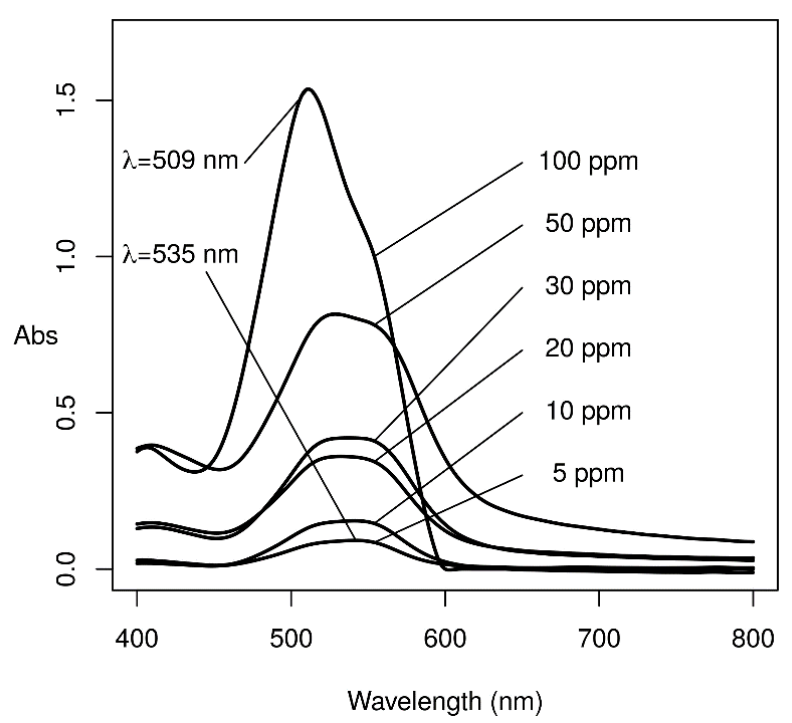

Fig. 7. UV-Visible absorption spectra of the DR81 at different concentration values in the presence of XANT $(1 \% \mathrm{w} / \mathrm{v}, \mathrm{pH}=4.0)$.

Fig. 8 depicts the electronic absorption spectra of DR81 in the XANT-DR81 and XANT-DR81-A1 compounds. The XANT-DR81-Al system suffered a bathocromic shift from $\lambda_{\max }=509 \mathrm{~nm}$ to $\lambda_{\max }=517 \mathrm{~nm}$ and a shoulder located at $560 \mathrm{~nm}$ appeared when $\mathrm{AlCl}_{3}$ aqueous solution was added to the XANT-DR81 adduct. The mechanism is similar to that observed in the XANT-DB1-Al system, but with a lower magnitude. This means that the CAL-13 and CAL-30 clusters attract the DR81 molecules and tend to fragment the aggregates contained in the XANT-DR81 adduct, as a result DR81 molecules with lower level of aggregation can be found in the XANT-DR81-Al system. We propose that there are at least two kinds of DR81 molecules: Those attracted to the polyhydroxyoxoaluminum cations, and other molecules adsorbed to XANT through hydrogen bonding and hydrophobic interactions that can be included in the network when the XANT-DR81-Al is formed.

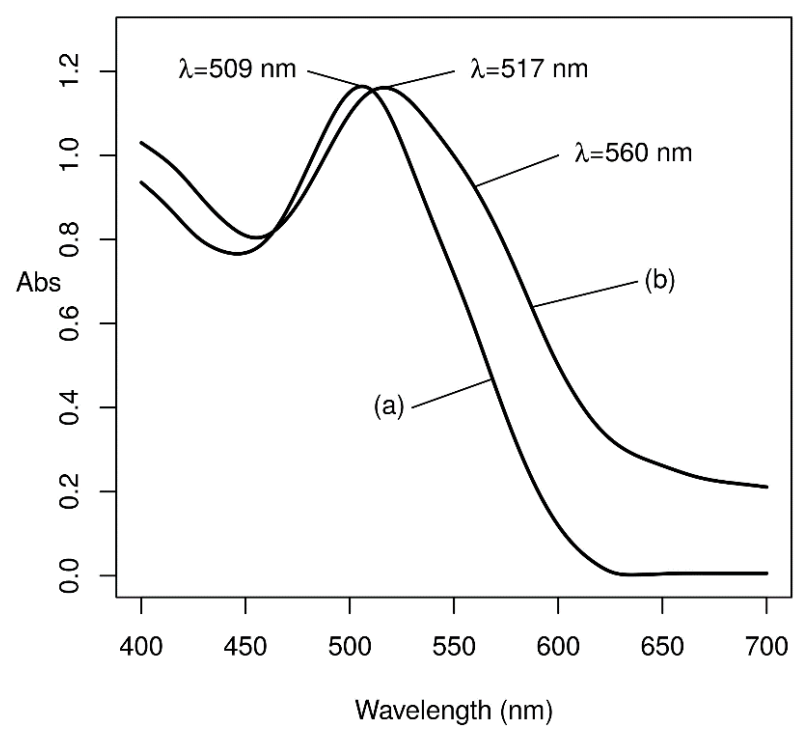

Fig. 8. UV-Visible absorption spectra of: (a) the XANT-DR81 adduct, and (b) XANT-DR81-Al gel. 
The figures $1(\mathbf{c})$ and 9 show that DB22 dye has both, azo and hydrazone tautomers, and they appear in the absorption electronic spectrum as a wide band located at $\lambda_{\max }=481 \mathrm{~nm}$ and a broad band at $620 \mathrm{~nm}$ that starts approximately at $500 \mathrm{~nm}$ and ends at $790 \mathrm{~nm}[65,66]$. From DB22 structure and in accordance with Oakes and Dixon [51], the presence of two naphthyl and four phenyl groups suggest that this dye has a great ability to form aggregates. Furthermore, the molecular weight is the biggest of the dyes used in this study and as a consequence, it is proposed that this compound forms the greatest and more stable aggregates reported in this work. This high stability is observed at concentrations as low as $5 \mathrm{ppm}$ (fig. 9), because $\lambda_{\max }=481 \mathrm{~nm}$ remains at this value at all concentration values at $\mathrm{pH}=4$.

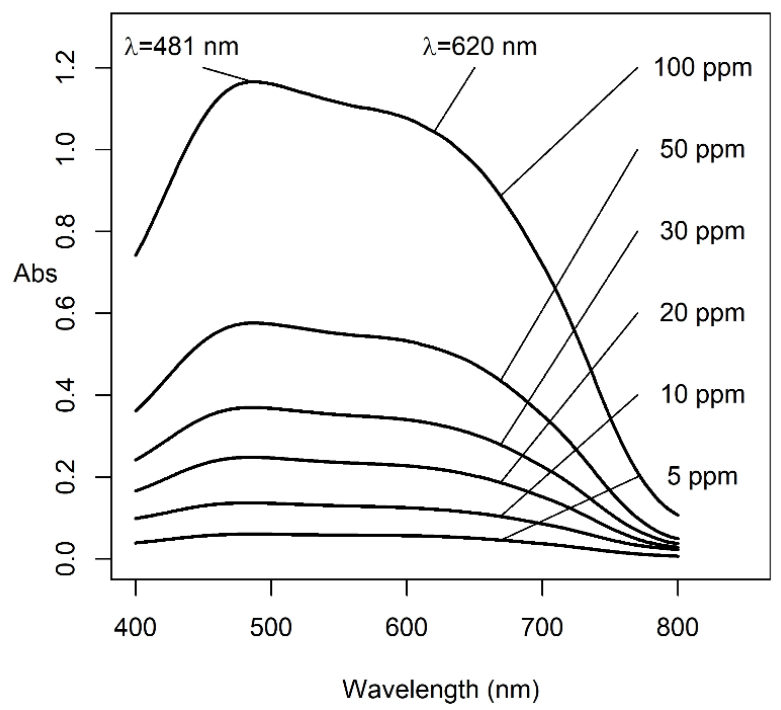

Fig. 9. UV-Visible absorption spectra of DB22 at different concentration values (5-100 ppm).

When DB22 interacts with XANT, it is observed a significant bathochromic shift from $\lambda_{\max }=481 \mathrm{~nm}$ to $\lambda_{\max }=510 \mathrm{~nm}$ in the first maximum from the electronic absorption spectrum of this dye, suggesting a defragmentation of DB22 aggregates similar to those observed with DB1 and DR81 dyes (see figures 9 and 10 a). Interestingly, the intensity of this maximum is decreased, but that located at $620 \mathrm{~nm}$ is increased, these findings can be attributed to a tautomeric shift to hydrazone form, and the resulting spectrum shows two broad maxima with equivalent intensities (see fig. 10 (a)).

To evaluate the effect of gel formation on DB22 dye when $\mathrm{AlCl}_{3}$ is added to the adduct XANT-DB22, the spectra of both compounds XANT-DB22 and XANT-DB22-Al were obtained (fig. 10(a) and (b) respectively). Notably, it was found that the spectrum changed, showing an increasing in the band intensity located at $620 \mathrm{~nm}$ but a slight decreasing in the intensity of the other band that appears at $481 \mathrm{~nm}$. These changes suggest a shift in the tautomeric equilibrium of DB22 molecules [67], favoring the hydrazone form as a consequence of the repulsion between these molecules and the clusters CAL-13 and CAL-30, but at the same time by the attraction occurred between XANT and DB22 molecules. These spectra suggest that DB22 molecules suffer an internal rearrangement, that favors their stability in the new environment that the XANTAl network offers, resulting in a high removal efficiency. 


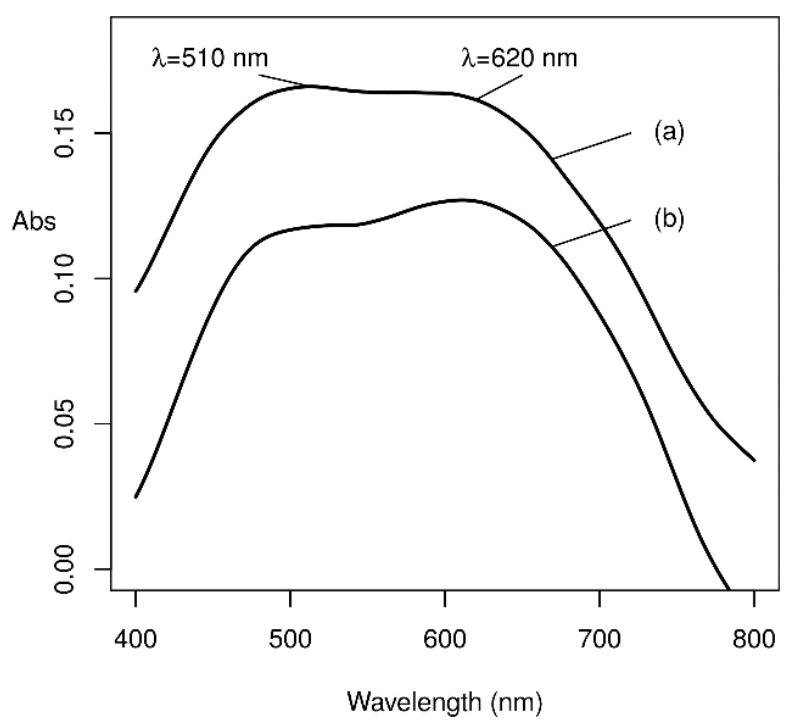

Fig. 10. UV-Visible absorption spectra of (a) XANT-DB22 and (b) XANT-DB22-Al.

\section{Infrared and Raman studies}

With the aim of gaining a better understanding of the XANT-Dye-Al system, the FT-IR and Raman spectroscopy techniques were used. Fig. 11 shows the FT-IR spectra of the following compounds: DB1, XANT$\mathrm{Al}$, and XANT-DB1-Al. In the spectrum of DB1 (fig. 11(a)), the typical asymmetrical and symmetrical vibrations $v_{\mathrm{s}}(\mathrm{NH})$ and $v_{\text {as }}(\mathrm{NH})$ can be found at $3290 \mathrm{~cm}^{-1}$ and $3425 \mathrm{~cm}^{-1}$ respectively, confirming the presence of the amino group in this dye. The signal corresponding to $v(\mathrm{C}=\mathrm{N})$ from hydrazone tautomeric form appears at $1565 \mathrm{~cm}^{-1}$ and the band located at $1045 \mathrm{~cm}^{-1}$ suggests the presence of $v(\mathrm{C}-\mathrm{O})$ from methoxy groups belonging to the DB1 molecule. It can be supposed that the location and identification of these signals in the FT-IR spectrum of the XANT-DB1-Al would be easy and unequivocal, but as can be observed in the fig. 11(c) and table 2, the vibrations $v_{\mathrm{as}}(\mathrm{NH})$ and $v_{\mathrm{s}}(\mathrm{NH})$ from DB1 cannot be observed in the XANT-DB1-Al due to the presence of a broad band centered at $3250 \mathrm{~cm}^{-1}$ corresponding to the $v(\mathrm{O}-\mathrm{H})$ vibration. The respective signal assigned to $v(\mathrm{C}=\mathrm{N})$ is located at $1563 \mathrm{~cm}^{-1}$ in the XANT-DB1-Al, which suggests that all molecules from this dye are contained in this compound as the hydrazone tautomer [68]. 


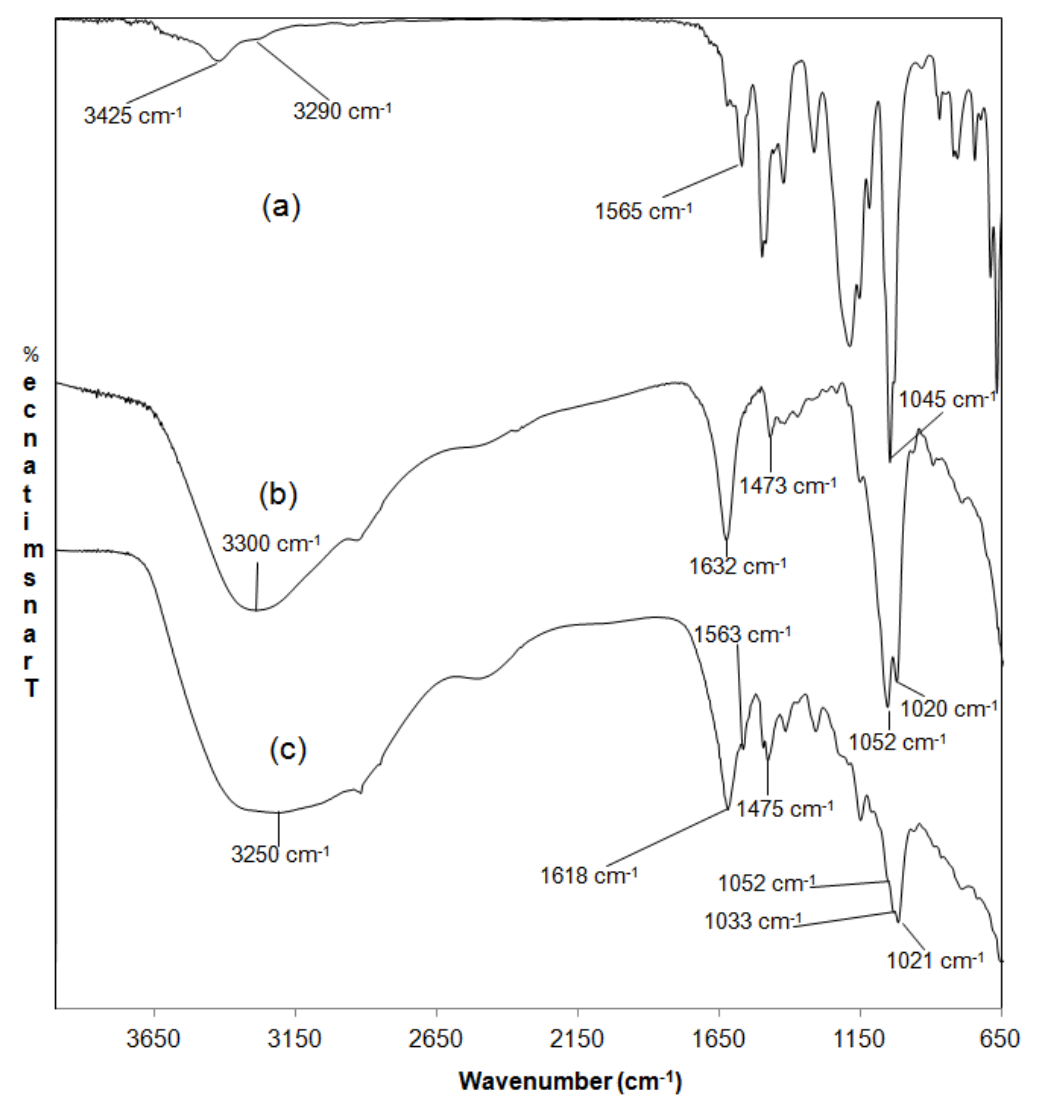

Fig. 11. FT-IR spectra of: (a) the DB1 dye, (b) XANT-Al, and (c) the product XANT-DB1-Al.

Table 2. FT-IR and Raman data of XANT-Al, DB1, and XANT-DB1-Al compounds.

\begin{tabular}{|c|c|c|c|l|}
\hline FT-IR signal & XANT-Al & DB1 & XANT-DB1-Al & Observations \\
\hline $\begin{array}{c}v_{\text {as }}(\mathrm{COO}) \text { From } \\
\text { pyruvate and } \\
\text { glucuronate group }\end{array}$ & $1632 \mathrm{~cm}^{-1}$ & & $1618 \mathrm{~cm}^{-1}$ & $\begin{array}{l}\text { Suggests the presence of } \\
\text { hydrogen bonding. }\end{array}$ \\
\hline $\begin{array}{c}v_{\mathrm{s}}(\mathrm{COO}) \text { From } \\
\text { pyruvate and } \\
\text { glucuronate groups }\end{array}$ & $1473 \mathrm{~cm}^{-1}$ & & $1475 \mathrm{~cm}^{-1}$ & $\begin{array}{l}\text { A slight change in vibration } \\
\text { frequency. }\end{array}$ \\
\hline $\begin{array}{c}v(\mathrm{C}-\mathrm{O}) \\
\text { frequency. }\end{array}$ & $1020 \mathrm{~cm}^{-1}$, & $1045 \mathrm{~cm}^{-1}$ & $\begin{array}{l}1033 \mathrm{~cm}^{-1}, 1021 \\
\mathrm{~cm}^{-1} \mathrm{and}^{-1} 1052 \\
\mathrm{~cm}^{-1}\end{array}$ & $\begin{array}{l}\text { There is an overlapping } \\
\text { between the peaks from } \\
\text { XANT and DB1 compounds. }\end{array}$ \\
\hline $\begin{array}{c}v(\mathrm{C}=\mathrm{N}) \text { from } \\
\text { hydrazone } \\
\text { tautomer }\end{array}$ & $1052 \mathrm{~cm}^{-1}$ & $1565 \mathrm{~cm}^{-1}$ & $\begin{array}{l}\text { This signal confirms the } \\
\text { presence of the DB1 dye in } \\
\text { its hydrazone form in } \\
\text { XANT-DB1-Al. }\end{array}$ \\
\hline$v_{\text {as }}(\mathrm{NH})$ & & $3425 \mathrm{~cm}^{-1}$ & $\begin{array}{c}\text { It is not } \\
\text { observable }\end{array}$ & $\begin{array}{l}\text { Broad hydrogen bonding } \\
\text { band prevents detecting this } \\
\text { signal. }\end{array}$ \\
\hline
\end{tabular}




\begin{tabular}{|c|l|l|l|l|}
\hline$v_{\mathrm{s}}(\mathrm{NH})$ & $3290 \mathrm{~cm}^{-1}$ & $\begin{array}{l}\text { It is not } \\
\text { observable }\end{array}$ & The same as above. \\
\hline Raman Signal & & & $1595 \mathrm{~cm}^{-1}$ & $\begin{array}{l}\text { This signal confirms the } \\
\text { presence of DB1 in XANT- } \\
\text { DB1-Al. }\end{array}$ \\
\hline $\begin{array}{c}v(\mathrm{C}=\mathrm{C}) \text { from } \\
\text { phenyl rings }\end{array}$ & $1566 \mathrm{~cm}^{-1}$ & $1565 \mathrm{~cm}^{-1}$ & $\begin{array}{l}\text { This signal confirms the } \\
\text { presence of the DB1 dye in } \\
\text { its hydrazone form in } \\
\text { XANT-DB1-Al. }\end{array}$ \\
\hline $\begin{array}{c}v(\mathrm{C}=\mathrm{N}) \text { from } \\
\text { hydrazone } \\
\text { tautomer }\end{array}$ & & & \\
\hline
\end{tabular}

The vibration $v(\mathrm{C}-\mathrm{O})$ that appears at $1052 \mathrm{~cm}^{-1}$ from methoxy groups remains in the same vibration frequency, but an overlap occurred with the peaks corresponding to $v(\mathrm{C}-\mathrm{O})$ from the sugar residues of XANT polysaccharide. If a comparison between fig. 11(b) and 11(c) is made, it is evident the similarity observed in the peaks originated by $v_{\mathrm{as}}(\mathrm{COO})$ and $v_{\mathrm{s}}(\mathrm{COO})$ from pyruvate and glucuronate groups identified at 1632-1618 $\mathrm{cm}^{-1}$ and 1473-1475 $\mathrm{cm}^{-1}$ respectively and from $v(\mathrm{OH})$ located at $3300 \mathrm{~cm}^{-1}$ and $3250 \mathrm{~cm}^{-1}$ in both the XANT$\mathrm{Al}$ and XANT-DB1-Al compounds respectively. The Raman spectra of DB1 and XANT-DB1-Al are depicted in the fig. 12. Unfortunately, the Raman spectrum of XANT-Al showed high fluorescence and it was not possible to assign any peak from it. As can be seen in the fig. 11 , the $v(C=C)$ from the phenyl rings $\left(1595 \mathrm{~cm}^{-}\right.$ $\left.{ }^{1}\right)$ and $v(\mathrm{C}=\mathrm{N})$ from the hydrazone form of DB1 $\left(1565 \mathrm{~cm}^{-1}\right)$ are observed in the Raman spectrum of XANTDB1-Al at $1595 \mathrm{~cm}^{-1}$ and $1563 \mathrm{~cm}^{-1}$ respectively, which confirm the presence of the DB1 in the XANT-DB1Al compound [69].

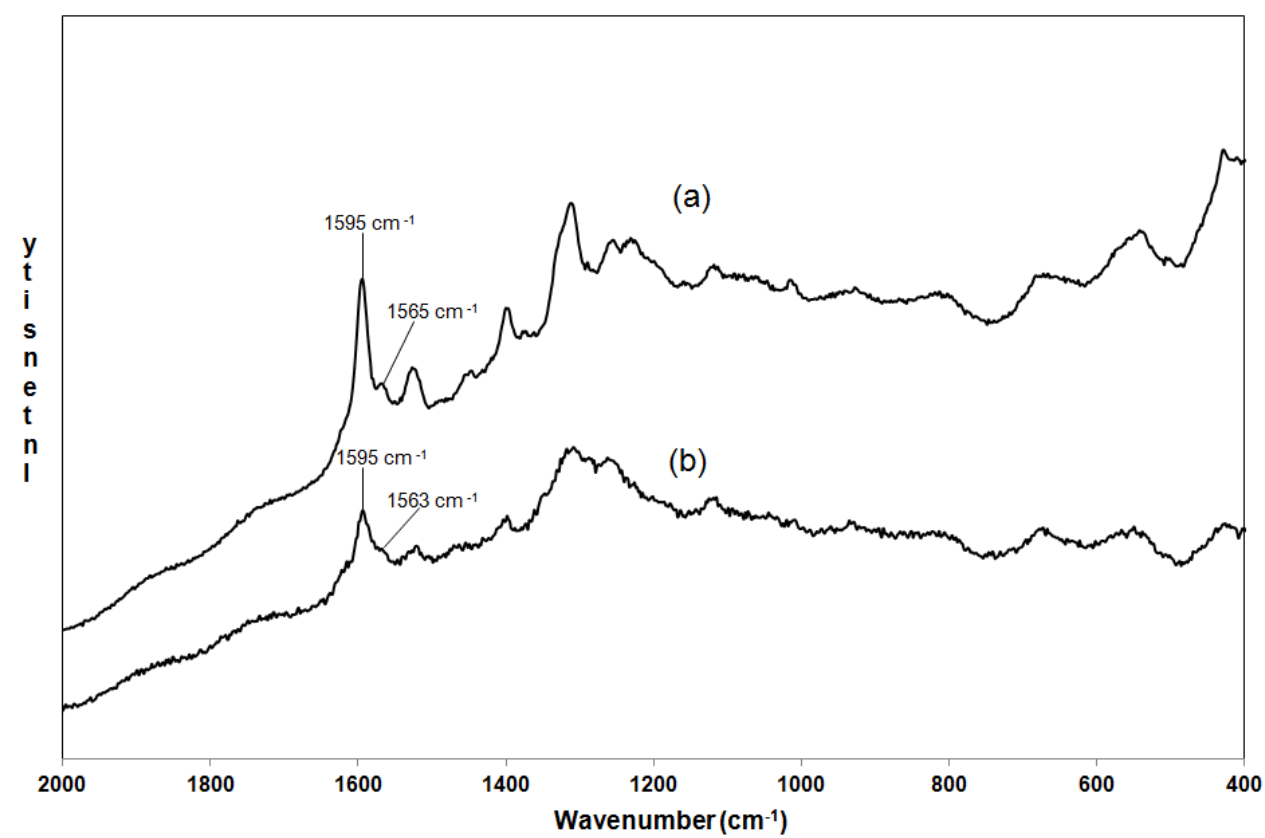

Fig. 12. Raman spectra of: (a) the DB1 dye, and (b) the product XANT-DB1-Al.

Table 3 includes the FT-IR and Raman data of the XANT-A1, DR81, and XANT-DR81-Al compounds. In the same manner as in the XANT-DB1-Al, the main signals registered from the DR81 dye are overlapped with those bands originated from the XANT-Al compound, because both have similar vibration frequencies in 
the medium infrared range. Thereby both the $v(\mathrm{OH})$ from DR81 and the sugar residues from XANT-Al are located at 3440-3444 $\mathrm{cm}^{-1} v(\mathrm{C}=\mathrm{O})$ located at $1602 \mathrm{~cm}^{-1}$, the characteristic vibration of the amide group attached to the DR81 molecule is difficult to identify due to overlapping with vibrations from the carboxylate (from glucuronate and pyruvate groups) unit. In addition, the $v_{s}(\mathrm{COO})$ and $v_{\mathrm{s}}(\mathrm{C}=\mathrm{O})$ from acetyl group remains in the XANT-Al and XANT-DR81-Al suggesting similar chemical environments (see table 3).

Table 3. FT-IR and Raman data of XANT-Al, DR81 and XANT-DR81-Al compounds.

\begin{tabular}{|c|c|c|c|c|}
\hline FT-IR signal & XANT-AI & DR81 & XANT-DR81-AI & Observations \\
\hline$v(\mathrm{OH})$ & $3440 \mathrm{~cm}^{-1}$ & $3444 \mathrm{~cm}^{-1}$ & $3500 \mathrm{~cm}^{-1}$ & $\begin{array}{l}\text { Hydrogen bonding still exists } \\
\text { in XANT-DR81-Al. }\end{array}$ \\
\hline $\begin{array}{l}v(\mathrm{C}=\mathrm{O}) \text { from } \\
\text { acetyl group }\end{array}$ & $1730 \mathrm{~cm}^{-1}$ & & $1728 \mathrm{~cm}^{-1}$ & Without changes. \\
\hline$v_{\text {as }}(\mathrm{COO})$ & $1634 \mathrm{~cm}^{-1}$ & & $1630 \mathrm{~cm}^{-1}$ & $\begin{array}{l}\text { The electrostatic interaction } \\
\text { between the carboxylate } \\
\text { groups with polyhydroxo- } \\
\text { aluminum cations is similar in } \\
\text { XANT-Al and XANT-DR81- } \\
\text { Al. }\end{array}$ \\
\hline$v_{\mathrm{s}}(\mathrm{COO})$ & $1430 \mathrm{~cm}^{-1}$ & & $1430 \mathrm{~cm}^{-1}$ & The same as above. \\
\hline$v(\mathrm{C}=\mathrm{O})$ & & $1602 \mathrm{~cm}^{-1}$ & $\begin{array}{c}\text { It is not } \\
\text { distinguishable. }\end{array}$ & $\begin{array}{l}\text { The signal of DR81 is } \\
\text { overlapped with the } v_{\text {as }}(\mathrm{COO}) \\
\text { signal from XANT-Al in } \\
\text { XANT-DR81-Al. }\end{array}$ \\
\hline \multicolumn{5}{|l|}{ Raman signal } \\
\hline $\begin{array}{l}v(\mathrm{C}=\mathrm{C}) \text { from } \\
\text { phenyl rings }\end{array}$ & & $1595 \mathrm{~cm}^{-1}$ & $1595 \mathrm{~cm}^{-1}$ & $\begin{array}{l}\text { This signal confirms the } \\
\text { presence of DR81 in XANT- } \\
\text { DR81-Al. }\end{array}$ \\
\hline $\begin{array}{c}v(\mathrm{C}=\mathrm{N}) \text { from } \\
\text { hydrazone form }\end{array}$ & & $1563 \mathrm{~cm}^{-1}$ & $1561 \mathrm{~cm}^{-1}$ & $\begin{array}{l}\text { This signal suggests the } \\
\text { presence of the hydrazone } \\
\text { form in the XANT-DR81-Al } \\
\text { compound. }\end{array}$ \\
\hline $\begin{array}{c}v(\mathrm{~N}=\mathrm{N}) \text { from azo } \\
\text { tautomer }\end{array}$ & & $1443 \mathrm{~cm}^{-1}$ & $1445 \mathrm{~cm}^{-1}$ & $\begin{array}{l}\text { This signal suggests the } \\
\text { presence of the azo form in } \\
\text { XANT-DR81-Al compound. }\end{array}$ \\
\hline$v\left(-\mathrm{SO}_{3}\right)$ & & $\begin{array}{l}1133 \text { and } \\
1117 \mathrm{~cm}^{-1}\end{array}$ & 1132 and $1115 \mathrm{~cm}^{-1}$ & $\begin{array}{l}\text { Both signals confirm the } \\
\text { presence of DR81 in XANT- } \\
\text { DR81-Al. }\end{array}$ \\
\hline
\end{tabular}

On the other hand, the Raman spectra signals confirm the presence of DR81 dye in the XANT-DR81 product. For example, the vibration $v(\mathrm{C}=\mathrm{C})$ from the phenyl rings and the $v_{\mathrm{s}}\left(-\mathrm{SO}_{3}\right)$ located at $1595 \mathrm{~cm}^{-1}$ and $1115-1132 \mathrm{~cm}^{-1}$ respectively, show that DR81 is contained in the XANT-DR81-Al compound. Interestingly, the presence of the two tauotmeric forms of DR81 (hydrazone and azo) is inferred from the vibrations modes $v(\mathrm{C}=\mathrm{N})$ and $v(\mathrm{~N}=\mathrm{N})$ observed at $1561 \mathrm{~cm}^{-1}$ and $1445 \mathrm{~cm}^{-1}$ respectively in both, DR81 dye and XANT-DR81Al compounds. Moreover, it was found that the azo vibration intensity is higher when compared to the hydrazone form, indicating that the predominant tautomer in the XANT-DR81-Al product is the azo form in the solid state $[70,71]$.

Table 4 summarizes the main FT-IR and Raman signals found in the XANT-Al, DB22 and XANTDB22-Al compounds. As was seen in the ALG-DR81-Al system, some of the principal signals from DB22 are overlapped with the peaks corresponding to XANT-Al, which in turn, prevents confirming the presence of this dye in the XANT-DB22-Al. In this sense, the $v_{\text {as }}(\mathrm{NH})$ and $v_{\mathrm{s}}(\mathrm{NH})$ from DB22 located at $3380 \mathrm{~cm}^{-1}$ and 3260 
$\mathrm{cm}^{-1}$ respectively are immersed in the broad band corresponding to $v(\mathrm{OH})$ from XANT-Al centered at $3500 \mathrm{~cm}^{-}$ ${ }^{1}$ in the XANT-DB22-Al. The peaks from the $v(\mathrm{C}=\mathrm{O})$ vibration included in the hydrazone tautomer, whose vibration peaks were located at 1626 and $1622 \mathrm{~cm}^{-1}$ from DB22, appeared close to the signal $v_{\text {as }}(\mathrm{COO})$ located at $1621 \mathrm{~cm}^{-1}$ that corresponds to the carboxylate groups from glucuronate and pyruvate that are interacting through electrostatic interactions with the polyhydroxyoxoaluminum clusters; this proximity between these signals avoids to differentiate between them. Additionally, the vibration frequency of acetyl group attached to XANT-Al and XANT-DB22-Al products is similar, which suggests that this functional group does not interact with the DB22 molecule.

Table 4. FT-IR and Raman data of XANT-Al, DB22, and XANT-DB22-Al compounds.

\begin{tabular}{|c|c|c|c|c|}
\hline FT-IR signal & XANT-Al & DB22 & XANT-DB22-Al & Observations \\
\hline$v(\mathrm{OH})$ & $3500 \mathrm{~cm}^{-1}$ & 3444 & $3500 \mathrm{~cm}^{-1}$ & $\begin{array}{l}\text { Hydrogen bonding still exists in } \\
\text { XANT-DB22-Al. }\end{array}$ \\
\hline $\begin{array}{l}v(\mathrm{C}=\mathrm{O}) \text { from } \\
\text { acetyl group }\end{array}$ & $1729 \mathrm{~cm}^{-1}$ & & $1728 \mathrm{~cm}^{-1}$ & Without changes. \\
\hline$v_{\text {as }}(\mathrm{COO})$ & $1647 \mathrm{~cm}^{-1}$ & & $1621 \mathrm{~cm}^{-1}$ & $\begin{array}{l}\text { A shift in vibration frequency due } \\
\text { to electrostatic interaction } \\
\text { between the carboxylate groups } \\
\text { with polyhydroxo-aluminum } \\
\text { cations and DB22. }\end{array}$ \\
\hline$v_{\mathrm{s}}(\mathrm{COO})$ & $1415 \mathrm{~cm}^{-1}$ & & $1434 \mathrm{~cm}^{-1}$ & The same as above. \\
\hline$v_{\mathrm{as}}(\mathrm{NH})$ & & $\begin{array}{l}3380 \\
\mathrm{~cm}^{-1}\end{array}$ & Not observable & $\begin{array}{l}\text { Broad hydrogen bonding band } \\
\text { prevents detecting this signal. }\end{array}$ \\
\hline$v_{\mathrm{s}}(\mathrm{NH})$ & & $\begin{array}{l}3260 \\
\mathrm{~cm}^{-1}\end{array}$ & Not observable & The same as above. \\
\hline$v(\mathrm{C}=\mathrm{O})$ & & $\begin{array}{l}1626 \\
\mathrm{~cm}^{-1} \\
1622 \\
\mathrm{~cm}^{-1}\end{array}$ & $1621 \mathrm{~cm}^{-1}$ & $\begin{array}{l}\text { The signal of DB22 is overlapped } \\
\text { with the } v_{\text {as }}(\mathrm{COO}) \text { signal from } \\
\text { XANT-Al in XANT-DB22-Al. }\end{array}$ \\
\hline \multicolumn{5}{|l|}{ Raman signal } \\
\hline $\begin{array}{l}v(\mathrm{C}=\mathrm{C}) \text { from } \\
\text { phenyl rings }\end{array}$ & & $\begin{array}{l}1608 \\
\mathrm{~cm}^{-1}\end{array}$ & $1609 \mathrm{~cm}^{-1}$ & $\begin{array}{l}\text { This signal confirms the presence } \\
\text { of DB22 in XANT-DB22-Al. }\end{array}$ \\
\hline $\begin{array}{c}v(\mathrm{C}=\mathrm{N}) \text { from } \\
\text { hydrazone form }\end{array}$ & & $\begin{array}{l}1554 \\
\mathrm{~cm}^{-1}\end{array}$ & $1552 \mathrm{~cm}^{-1}$ & $\begin{array}{l}\text { This signal suggests the presence } \\
\text { of the hydrazone form in the } \\
\text { XANT-DB22-Al compound. }\end{array}$ \\
\hline $\begin{array}{l}v(\mathrm{~N}=\mathrm{N}) \text { from azo } \\
\text { tautomer }\end{array}$ & & $\begin{array}{l}1423 \\
\mathrm{~cm}^{-1}\end{array}$ & $1421 \mathrm{~cm}^{-1}$ & $\begin{array}{l}\text { This signal suggests the presence } \\
\text { of the azo form in the XANT- } \\
\text { DB22-Al compound. }\end{array}$ \\
\hline $\begin{array}{l}v(\mathrm{C}=\mathrm{C}) \text { from } \\
\text { naphthyl rings }\end{array}$ & & $\begin{array}{l}1240 \\
\mathrm{~cm}^{-1}\end{array}$ & $1239 \mathrm{~cm}^{-1}$ & $\begin{array}{l}\text { This signal confirms the presence } \\
\text { of DB22 in XANT-DB22-Al. }\end{array}$ \\
\hline$v\left(-\mathrm{SO}_{3}\right)$ & & $\begin{array}{l}1166 \\
\mathrm{~cm}^{-1}\end{array}$ & $1165 \mathrm{~cm}^{-1}$ & Same as above. \\
\hline
\end{tabular}

Unlike the FT-IR data, the signals found in the Raman spectra allow us to confirm the presence of DB22 in the XANT-DB22-Al. From Table 4, it can be seen that the peaks located at $1608 \mathrm{~cm}^{-1}, 1240 \mathrm{~cm}^{-1}$, and $1166 \mathrm{~cm}^{-1}$ which were assigned to $v(\mathrm{C}=\mathrm{C})$ from phenyl, naphthyl rings, and $v\left(-\mathrm{SO}_{3}\right)$ from the sulfonate groups respectively, appeared in similar vibration frequencies in the XANT-DB22-Al, mainly $v_{\text {phenyl }}(\mathrm{C}=\mathrm{C})=1609 \mathrm{~cm}^{-1}, v_{\text {naphthyl }}(\mathrm{C}=\mathrm{C})=1239 \mathrm{~cm}^{-1}$, and $v\left(-\mathrm{SO}_{3}\right)=1165 \mathrm{~cm}^{-1}$. Moreover, the signals corresponding to azo $\left(1421 \mathrm{~cm}^{-1}\right)$ and hydrazone tautomers $\left(1552 \mathrm{~cm}^{-1}\right)$, are found in both DB22 and XANT-DB22-Al confirming the results obtained by UV-Visible studies. 
To confirm the entrapment of dyes within the polymer matrix, solubility tests were performed. It was observed that the XANT-Dye-Al products exhibit differences in ethanol solubility. In this sense the dye released into the ethanol phase followed the order: DR81 $>$ DB1 $>$ DB22. It means that in the XANT-DB22-Al system no lixiviation of DB22 was observed after ethanol addition, suggesting that the leading interactions involved in the removal of this dye are of electrostatic nature. The DB1 was only dissolved at very low concentrations into the ethanol phase, which indicates that there is another interaction in conjunction with the coulombic forces that bind this dye to the XANT-Al product; as we proposed previously, hydrogen bonding and hydrophobic interactions can be involved in the removal of DB1 by using XANT as removal agent. In the case of the XANT-DR81-Al system, we observed the greatest amount of DR81 lixiviated in ethanol when this solvent was mixed with that product, thus being evident that this system involves the hydrogen bonding and hydrophobic interactions among the DR81 and the XANT molecules in a greater magnitude than the electrostatic interactions thus having a higher solubility of this dye into the ethanol phase.

As was mentioned before, the different functional groups of these dyes, and in consequence their charge, molecular weight, size, and aggregation capacity are involved in the removal of these substances by XANT. On the other hand, the XANT molecule has functional groups and hydrophobic regions that allow the interaction with dyes through distinct mechanisms such as hydrogen bonding, electrostatic and hydrophobic interactions. Furthermore, the addition of $\mathrm{AlCl}_{3}$ aqueous solution which contains polyhydroxyoxoaluminum clusters (CAL-13 and CAL-30) reacts with XANT producing a network where these positively charged clusters attract the XANT molecules which have a net negative charge and "traps" dye molecules, favoring high removal efficiencies of DB1, DR81 and DB22 dyes.

Based on all these factors, we do propose that when the XANT polymer is used as removal agent to decrease azo dyes in aqueous solution, the dyes with a higher negative charge, greater molecular weight, and higher aggregation capacity are more efficiently removed by this polysaccharide, which results in higher nucleation and cooperativity parameters ( $\mathrm{Ku}$ and $\mathrm{U}$ respectively).

Taking into account these points, we consider that the treatment with XANT can be applied to remove different azo dyes; in consequence, this biopolymer can be considered as a sustainable option to remove azo dyes.

\section{Conclusion}

The study of the removal of three azo dyes (DB1, DR81, and DB22) with XANT showed a higher removal capacity when this biopolymer is applied in conjunction with $\mathrm{AlCl}_{3}$, resulting in the following removal efficiencies: DB1 $(99 \%$ at $\mathrm{pH}=12$ and ionic strength $=0.1 \mathrm{M})$, DB22 $(99 \%$ at $\mathrm{pH}=4$ and ionic strength $=0.1 \mathrm{M})$ and $\mathrm{DR} 81(95 \%$ at $\mathrm{pH}=4$ and ionic strength $=0.9 \mathrm{M})$. The experimental isotherms were described adequately by the Zimm Bragg theory, the nucleation $(\mathrm{Ku})$ and cooperativity $(\mathrm{U})$ parameters included in this model were determined, resulting in the following order in the $\mathrm{Ku}$ and $\mathrm{U}$ values: XANT-DB1-Al> XANT-DB22-Al> XANT-DR81-A1.

The reaction of XANT with polyhydroxyoxoaluminum clusters (CAL-13 and CAL-30) give rise to a network, whose clusters attracts the dyes with a force that is directly proportional to the negative dye charge but at the same time, XANT molecules adsorb dyes through, hydrogen bonding and hydrophobic interactions. Once the network is formed, the dyes are "trapped" inside the cavities included in the XANT-Al product resulting in high removal efficiencies of DB1, DB22 and DR81 dyes. It may be concluded that the XANT polymer is a good option to remove azo dyes from an aqueous medium.

\section{Acknowledgements}

We gratefully acknowledged the support for this project by National Council for the Science and Technology, CONACYT, México (GRANT No.9502). The authors wish to thank Dr. Carlos Peña-Malacara 
(Instituto de Biotecnología de la Universidad Nacional Autónoma de México) for the molecular weight determination of the xanthan used in this work.

\section{References}

1. Freeman H.S.; Mock G.N., In: Handbook of industrial chemistry and Biotechnology, Kent, J.A., Ed., Springer, Boston, EUA, 2012, 475-548. DOI: 10.1007/978-1-4614-4259-2_13

2. Holme, I., in: Handbook of Technical Textiles; $2^{\text {nd }}$. ed., Vol.1, Horrocks, A. R.; Anand, S. C., Eds., Woddhead Publishing, Cambridge, 2015, 231-284.

3. Yagub, M. T.; Sen, T. K.; Afroze, S.; Ang, H M. Adv. Colloid Interface Sci. 2014, 209, $172-184$ DOI: http://dx.doi.org/10.1016/j.cis.2014.04.002

4. Gulrez, S. K. H.; Al-Assafa, S.; Fang, Y.; Phillips, G. O.; Gunning, A. P. Carbohydr. Polym. 2012, 90, 1235-1243 DOI: http://dx.doi.org/10.1016/j.carbpol.2012.06.055

5. Makhado, E.; Pandey, S.; Nomngongo, P. N.; Ramontja, J. Carbohydr. Polym. 2017, 176, 315-326 DOI: http://dx.doi.org/10.1016/j.carbpol.2017.08.093

6. Mittal, H.; Parashar, V.; Mishra, S. B.; Mishra, A. K. Chem. Eng. J. 2014, 255, 471-482 DOI: http://dx.doi.org/10.1016/j.cej.2014.04.098

7. Ghorai, s.; Sarkar, A. K.; Panda, A. B.; Pal, S. Biores. Technol. 2013, 144, $485-491$ DOI: http://dx.doi.org/10.1016/j.biortech.2013.06.108

8. Ghorai, S.; Sarkar, A.; Raoufi, M.; Panda, A. B.; Schönherr, H.; Pal, S. ACS Appl. Mater. Interfaces 2014, 6, 4766-4777 DOI: http://dx.doi.org/10.1021/am4055657

9. Pandey, S.; Mishra, S. V. Carbohydr. Polym. 2012, 90, 370-379. DOI: http://dx.doi.org/10.1016/j.carbpol.2012.05.053

10. Pal, A.; Majumder, K.; Bandyopadhyay, A. Carbohydr. Polym. 2016, 152, 41-50. DOI: http://dx.doi.org/10.1016/j.carbpol.2016.06.064

11. Iftekhar, S.; Srivastava, V.; Hammouda, S. B.; Sillanpääa, M. Carbohydr. Polym. 2018, 194, $274-284$. DOI: https://doi.org/10.1016/j.carbpol.2018.04.054

12. Xin, J.; Han, J.; Zheng, X.; Shao, H.; Kolditz, O. J. Environ. Manage. 2015, 150, 420-426. DOI: http://dx.doi.org/10.1016/j.jenvman.2014.12.022

13. Chen, X.; Li, P.; Kang, Y.; Zeng, X.; Xie, Y.; Zhang, Y.; Wang, Y.; Xie, T. Carbohydr. Polym. 2019, 206, 94-101. DOI: https://doi.org/10.1016/j.carbpol.2018.10.092

14.Zhang, Q.; Hua, X. M.; Wu, M. Y.; Wang, M. M.; Zhao, Y. Y.; Li, T. T. React. Funct. Polym. 2019, 136, 34-43. DOI: https://doi.org/10.1016/j.reactfunctpolym.2019.01.002

15.Li, $\mathrm{M}$ and Buschle-Diller, G. Int. J. Biol. Macromol. 2017, 101, 481-489. DOI:http://dx.doi.org/10.1016/j.ijbiomac.2017.03.091

16. Chaudhary, S.; Sharma, J.; Kaith, B. S.; Yadav, S.; Sharma, A. K.; Goel, A. Ecotoxicol. Environ. Saf. 2018, 149, 150-158 DOI: https://doi.org/10.1016/j.ecoenv.2017.11.030

17. Zheng, M.; Lian, F.; Xiong, Y.; Liu, B.; Zhu, Y.; Miao, S.; Zhang, L.; Zheng, B. Food Chem. 2019, 272, 574-579. DOI: https://doi.org/10.1016/j.foodchem.2018.08.083

18. Sukriti; Sharma, J.; Pruthi, V.; Anand, P.; Chaddha, A. P. S.; Bhatia, J.; Kaith, B. S. RSC Adv. 2016, 6, 74300-74313. DOI: https://doi.org/10.1039/c6ra12715k

19. Sukriti; Sharma, J.; Chadha, A. S.; Pruthi, V.; Anand, P.; Bhatia, J.; Kaith, B. S. J. Environ. Manage. 2017, 190, 176-187. DOI: http://dx.doi.org/10.1016/j.jenvman.2016.12.065

20. Sharma, J.; Sukriti; Anand, P.; Pruthi, V.; Chaddha, A. S.; Bhatia, J.; Kaith, B. S. Mater. Chem. Phys. 2017, 196, 270-283. DOI: : http://dx.doi.org/0.1016/j.matchemphys.2017.04.042

21. Sharma, A. K.; Priya; Kaith, B. S.; Bajaj, S.; Bhatia, J. K.; Panchal, S.; Sharma, N.; Tanwar, V. Colloid. Surface. B. 2019, 175, 314-323. DOI: https://doi.org/10.1016/j.colsurfb.2018.12.017

22. Mittal, H.; Kumar, v., Saruchi; Ray, S. S. Int. J. of Biol. Macromol. 2016, 89, 1-11 DOI: http://dx.doi.org/10.1016/j.ijbiomac.2016.04.050

23. Thakur, S.; Pandey, S.; Arotiba, O. A. Int. J. of Biol. Macromol. 2017, 103, 596-604 DOI: http://dx.doi.org/10.1016/j.ijbiomac.2017.05.087 
24. Kaith, B. S.; Sukriti; Sharma, J.; Kaur, T.; Sethi, S.; Shanker, U.; Jassal, V. Iran. Polym. J. 2016, 25, 787-797 DOI: http://dx.doi.org/10.1007/s13726-016-0467-z

25. Makhado, E.; Pandey, S.; Ramontja, J. Int. J. Biol. Macromol. 2018, 119, 255-269. DOI: https://dx.doi.org/10.1016/j.ijbiomac.2018.07.104

26. Makhado, E.; Pandey, S.; Nomngongo, P. N.; Ramontja, J. J. Colloid Interf. Sci. 2018, 513, 700-714 DOI: https://dx.doi.org/10.1016/j.jcis.2017.11.060

27. Ahmad, R.; Mirza, A. Surf. Interfaces 2017, 8, 65-72 DOI: http://dx.doi.org/10.1016/j.surfin.2017.05.001

28. Jakóbik-Kolon, A.; Bok-Badura, J.; A. K. Milewski, A. K.; Mitko, K. Sep. Sci. Technol. 2018, 53, 1132-1141. DOI: http://dx.doi.org/10.1080/01496395.2017.1298613

29. Zheng, M.; Lian, F.; Zhu, Y.; Zhang, Y.; Liu, B.; Zhang, L.; Zheng, B. Carbohydr. Polym. 2019, 210, 38-46. DOI: https://doi.org/10.1016/j.carbpol.2019.01.052

30. Ghorai, S.; Sinhamahpatra, A.; Asish Sarkar A.; Panda, A. B.; Pal, S. Bioresour. Technol. 2012, 119, 181-190. DOI: http://dx.doi.org/10.1016/j.biortech.2012.05.063

31.Peng, X.; Xu, F.; Zhang, W.; Wang, J.; Zeng, C.; Niu, M.; Chmielewská, E. Colloid Surface A. 2014, 443, 27-36. DOI: http://dx.doi.org/10.1016/j.colsurfa.2013.10.062

32.Zhang, S.; Xu, F.; Wang, Y.; Zhang, W.; Peng, X.; Pepe, F. Chem Eng J. 2013, 234, 33-42. DOI: http://dx.doi.org/10.1016/j.cej.2013.08.102

33. Koohi, A. D.; Nasimi, F. Chem. Eng. Commun. 2017, 204 (7), 791-802. DOI: http://dx.doi.org/10.1080/00986445.2017.1322071

34. Ahmad, R.; Mirza, A. Groundwat. Sust. Developm. 2018, 7, 101-108. DOI:https://doi.org/10.1016/j.gsd.2018.03.010

35.Zhang, W.; Xu, F.; Wang, Y.; Luo, M.; Wang, D. Chem Eng J. 2014, 255, 316-326. DOI:http://dx.doi.org/10.1016/j.cej.2014.06.024

36. Perotti, G. F.; Kijchavengkul, T.; Auras, R. A.; Constantino, V.R.L. J. Braz. Chem. Soc. 2017, 28, 649658 DOI: http://dx.doi.org/10.21577/0103-5053.20160213

37. Patwary, F.; Matsko, N.; Mittal, V. Polym. Compos. 2016, 39, 386-397. DOI: https://dx.doi.org/10.1002/pc.23947

38. Gaurav, A.; Ashamol, A.; Deepthi, M. V.; Sailaja, R. R. N. J. Appl. Polym. Sci. 2012, 125, E16-E26 DOI: https://dx.doi.org/10.1002/app.35591

39.Zimm, B.H.; Bragg, J.K. J. Chem. Phys. 1959, 3, 526-535 DOI: https://dx.doi.org/10.1063/1.1730390

40. R Core Team. $R$ : A language and Environment for statistical computing. $R$ Foundation for Statistical Computing, Vienna, Austria, 2014, http: //www.R-project.org/.

41. Abbot, L. C.; Batchelor, S. N.; Oakes, J.; Lindsay-Smith, J. R.; Moore, J. N. J. Phys. Chem. B 2004, 108, 13726-13735 DOI: https://doi.org/10.1021/jp0485542

42. Sato, T.; Norisuye, T.; Fujita, H. Macromolecules 1984, 17, 2696-2700 DOI: https://dx.doi.org/10.1021/ma00142a043

43. Bejanariu, A.; Popa, M.; Le Cerf, D.; Picton, L. Polym. Bull. 2008, 61,631-641 DOI: https://dx.doi.org/10.1007/s00289-008-0987-6

44. Bejanariu, A.; Popa, M.; Dulong, V.; Picton, L.; Le Cerf, D. Polym. Bull. 2009, 62, 255-538 DOI: https://dx.doi.org/10.1007/s00289-008-0033-8

45. Rodd, A.B.; Dunstan, D.E.; Boger, D.V.; Schmidt, J.; Burchard, W. Macromol Symp. 2002, 190, 7991 DOI: https://dx.doi.org/10.1002/masy.200290022

46. Rodd, A. B.; Cooper-White, J.; Dunstan, D. E.; Boger, D. V. Polymer 2001, 42, 185-198 DOI: https://dx.doi.org/10.1016/S0032-3861(00)00311-6

47. Rodd, A.B.; Dunstan, D.E.; Boger, D.V.; Schmidt, J.; Burchard, W. Macromolecules 2001, 34, 33393352 DOI: https://dx.doi.org/10.1021/ma001706g.

48. Rowsell, J.; Nazar, L.F. J. Am. Chem. Soc. 2000, 122, 3777-3778 DOI: https://dx.doi.org/10.1021/ja993711+

49. Chen, Z.; Luan, Z.; Jia, Z.; Li, X. J. Mater. Sci. 2009, 44, 3098-3111 DOI: https://dx.doi.org/10.1007/s10853-009-3412-0

50. Young, S.L.; Martino, M.; Kienzle-Sterzer, C.; Torres, J. A. J. Sci. Food Agric. 1994, 64, 121-127 DOI: https://doi.org/10.1002/jsfa.2740640118 
51. Oakes, J.; Dixon, S. Rev. Prog. Color 2004, 34, 110-128 DOI: https://doi.org/10.1111/j.14784408.2004.tb00156.x

52. Langmuir, I. J. Am. Chem. Soc. 1916, 38, 2221-2295 DOI: https://doi.org/10.1021/ja02268a002

53. Freundlich, H. M. F. Z. Phys. Chem. 1906, 57, 385-470 DOI: https://doi.org/10.1515/zpch-1907-5723

54. Rafatullah, M.; Sulaiman, O.; Hashim, R.; Ahmad, A. J. Hazard. Mater. 2010, 177, 70-80 DOI: https://doi.org/10.1016/j.jhazmat.2009.12.047

55. Lozano-Alvarez, J. A.; Jáuregui-Rincón, J.; Mendoza-Díaz, G.; Rodríguez-Vázquez, R.; FraustoReyes, C. J. Mex. Chem. Soc. 2009, 53, 59-70.

56. Hayakawa, K.; Santerre, J. P.; Kwak, J. C. T. Macromolecules 1983, 16, 1642-1645 DOI: https://doi.org/10.1021/ma00244a017

57. Jain, N.; Trabelsi,S.; Guillot, S.; McLoughlin, D.; Langevin, D.;Letellier, P.; Mireille Turmine, M. Langmuir 2004, 20, 8496-8503 DOI: https://doi.org/10.1021/la0489918

58. Li, Y. M.; Xu, G. Y.; Chen, A. M.; Yuan, S. L. ; Cao, X. R. J. Phys. Chem. B 2005, 109, 22290-22295 DOI: https://doi.org/10.1021/jp0528414

59. Lozano-Álvarez, J. A.; Marañón-Ruíz, V. F.; Jáuregui-Rincón, J.; Medina-Ramírez, I.; Frausto-Reyes, C.; Salinas-Gutiérrez, R. J. Mex. Chem. Soc. 2015, 59, 215-227.

60. Oakes, J.; Gratton, P. J. Chem. Soc., Perkin Trans. 1998, 2, 1857-1864. DOI: https://doi.org/10.1039/A803892I

61. Sharma, K. K.; O’Neill, P.; Oakes, J.; Batchelor, S. N.; Madhava-Rao, B. S. J. Phys. Chem. A 2003, 107, 7619-7628 DOI: https://doi.org/10.1021/jp035002v

62. Karukstis, K. K.; Perelman, L. A.; Wong, W. K. Langmuir 2002, 18, 10363-10371 DOI: https://doi.org/10.1021/la020558f

63. Camesano, T. A.; Wilkinson, K. J. Biomacromolecules 2001, 2, 1184-1191 DOI: https://doi.org/10.1021/bm015555g

64. Abbott, L. C.; Batchelor, S. N.; Jansen, L.; Oakes, J.; Lindsay-Smith, J. R.; Moore, J. N. New J. Chem. 2004, 28, 815-821 DOI: https://doi.org/10.1039/B401055H

65. Vahdat, A.; Bahrami, S. H.; Arami, M.; Motahari, A. Radiat. Phys. Chem. 2010, 9, 33-35 DOI: https://doi.org/10.1016/j.radphyschem.2009.08.012

66. Michniewicz A.; Ledakowicz, S.; Ullrich, R.; Hofrichter, M. Dyes Pigm. 2008, 77, 295-302 DOI: https://doi.org/10.1016/j.dyepig.2007.05.015

67. Gregory, P., In: The Chemistry and application of dyes, Waring, D. R.; Geoffrey Ha1 1as, Eds., Plenum Press, New York. EUA, 1990, 17-47 DOI: https://doi.org/10.1007/978-1-4684-7715-3

68. Silverstein, R.M.; Webster, F. X.; Kiemle, D. J.; Bryce D.L. Spectrometric identification of organic compounds. 8a. ed. John Wiley and Sons, EUA, 2015, 453 pp.

69. Schrader B. In: Infrared and Raman spectroscopy, methods and applications, B. Schrader, B. Ed., VCH Verlagsgesellschaft mbH, Germany, 1995, 189-222. DOI: https://doi.org/10.1002/9783527615438

70. Armstrong, D. R.; Clarkson J.; Smith, W. E. J. Phys. Chem. 1995, 99, 17825-17831 DOI: https://doi.org/10.1021/j100051a005

71. Biswas, N.; Umapathy, S. J. Phys. Chem. A. 2000, 104, 2734-2745 DOI: https://doi.org/10.1021/jp9929263 